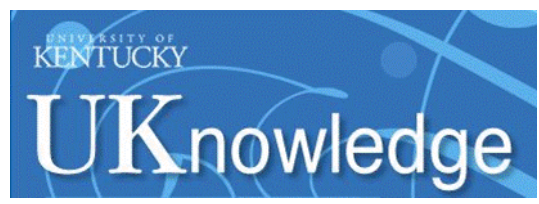

University of Kentucky

UKnowledge

\title{
$A \boldsymbol{\beta}$ Vaccination in Combination with Behavioral Enrichment in Aged Beagles: Effects on Cognition, $A \boldsymbol{\beta}$, and Microhemorrhages
}

\author{
Paulina R. Davis \\ University of Kentucky, pau.davis@uky.edu \\ Ginevra Giannini \\ Lovelace Respiratory Research Institute \\ Karin Rudolph \\ Lovelace Respiratory Research Institute \\ Nathaniel Calloway \\ University of Kentucky, nathaniel.calloway@uky.edu \\ Christopher M. Royer \\ Lovelace Respiratory Research Institute \\ Follow this and additional works at: https://uknowledge.uky.edu/sbcoa_facpub

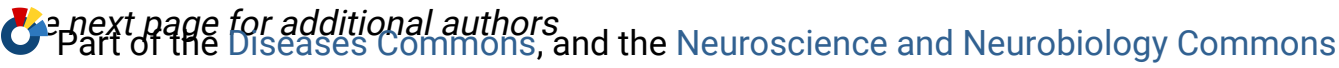 \\ Right click to open a feedback form in a new tab to let us know how this document benefits you.

\section{Repository Citation} \\ Davis, Paulina R.; Giannini, Ginevra; Rudolph, Karin; Calloway, Nathaniel; Royer, Christopher M.; Beckett, \\ Tina L.; Murphy, M. Paul; Bresch, Frederick; Pagani, Dieter; Platt, Thomas; Wang, Xiaohong; Donovan, Amy \\ Skinner; Sudduth, Tiffany L.; Lou, Wenjie; Abner, Erin L.; Kryscio, Richard J.; Wilcock, Donna M.; Barrett, \\ Edward G.; and Head, Elizabeth, "A $\beta$ Vaccination in Combination with Behavioral Enrichment in Aged \\ Beagles: Effects on Cognition, $A \beta$, and Microhemorrhages" (2017). Sanders-Brown Center on Aging \\ Faculty Publications. 126. \\ https://uknowledge.uky.edu/sbcoa_facpub/126
}

This Article is brought to you for free and open access by the Aging at UKnowledge. It has been accepted for inclusion in Sanders-Brown Center on Aging Faculty Publications by an authorized administrator of UKnowledge. For more information, please contact UKnowledge@lsv.uky.edu. 


\section{$A \boldsymbol{\beta}$ Vaccination in Combination with Behavioral Enrichment in Aged Beagles: Effects on Cognition, $A \boldsymbol{\beta}$, and Microhemorrhages}

Digital Object Identifier (DOI)

https://doi.org/10.1016/j.neurobiolaging.2016.09.007

Notes/Citation Information

Published in Neurobiology of Aging, v. 49, p. 86-99.

(C) 2016 Elsevier Inc. All rights reserved.

This manuscript version is made available under the CC-BY-NC-ND 4.0 license https://creativecommons.org/licenses/by-nc-nd/4.0/.

The document available for download is the author's post-peer-review final draft of the article.

\section{Authors}

Paulina R. Davis, Ginevra Giannini, Karin Rudolph, Nathaniel Calloway, Christopher M. Royer, Tina L. Beckett, M. Paul Murphy, Frederick Bresch, Dieter Pagani, Thomas Platt, Xiaohong Wang, Amy Skinner Donovan, Tiffany L. Sudduth, Wenjie Lou, Erin L. Abner, Richard J. Kryscio, Donna M. Wilcock, Edward G. Barrett, and Elizabeth Head 


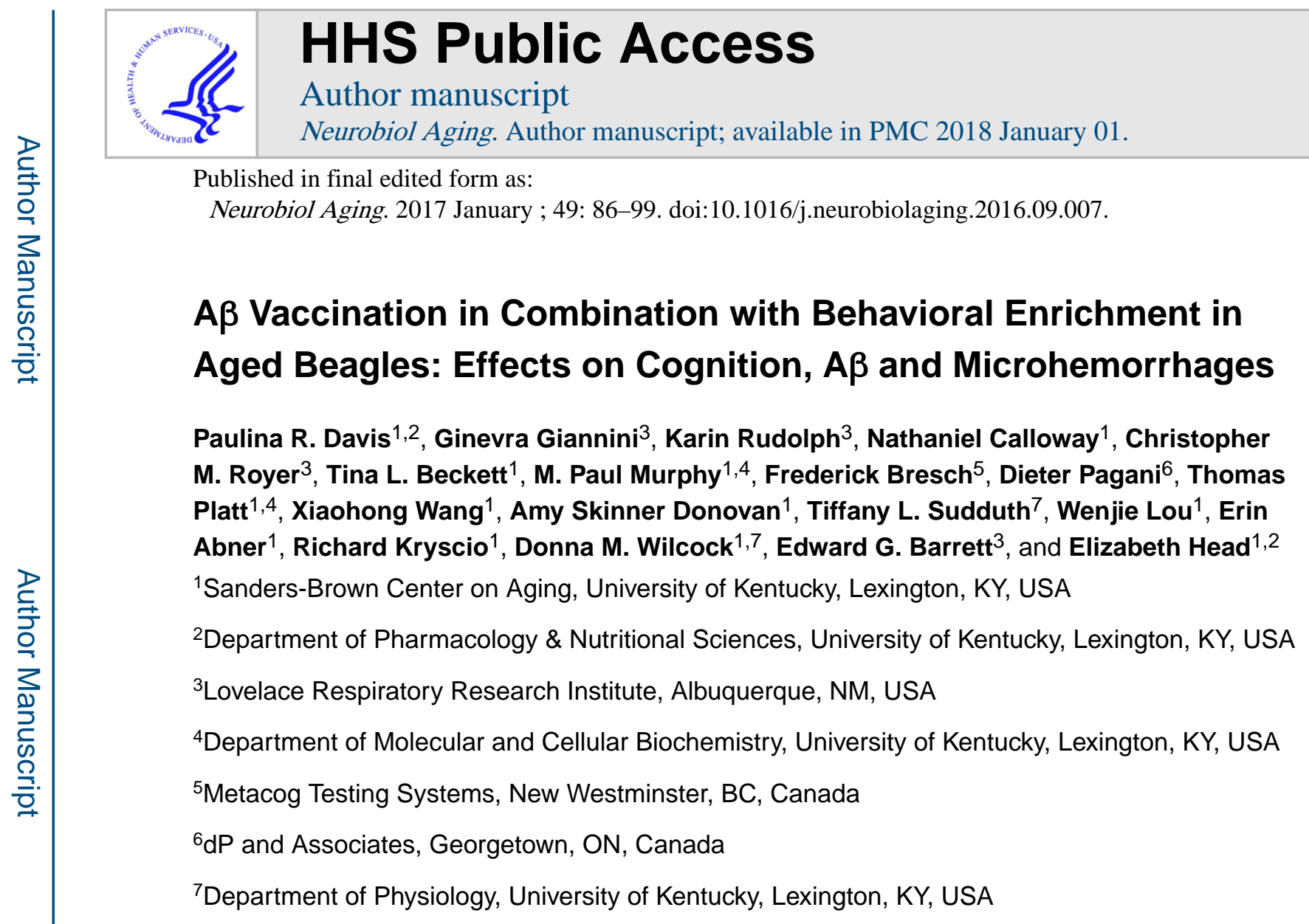

\section{Abstract}

Beta-amyloid (A $\beta$ ) immunotherapy is a promising intervention to slow Alzheimer's disease (AD). Aging dogs naturally accumulate $A \beta$ and show cognitive decline. An active vaccine against fibrillar A $\beta$ 1-42 (VAC) in aged beagles resulted in maintenance but not improvement of cognition along with reduced brain A $\beta$. Behavioral enrichment (ENR) led to cognitive benefits but no reduction in $A \beta$. We hypothesized cognitive outcomes could be improved by combining VAC with ENR in aged dogs. Aged dogs (11-12 years) were placed into 4 groups: (1) control/control (C/C); (2) control/VAC (C/V); (3) ENR/control (E/C); (4) ENR and VAC (E/V) and treated for 20 months. VAC decreased brain $A \beta$, pyroglutamate $A \beta$, increased CSF $A \beta 42$ and BDNF RNA levels but also increased microhemorrhages. ENR reduced brain $A \beta$ and prevented microhemorrhages. The combination treatment resulted in a significant maintenance of learning over time, reduced $A \beta$ and increased BDNF mRNA despite increased microhemorrhages, however there were no benefits to memory. These results suggest that the combination of immunotherapy with behavioral enrichment leads to cognitive maintenance associated with reduced neuropathology that may benefit people with AD.

Corresponding Author: Elizabeth Head, Ph.D, Sanders-Brown Center on Aging, University of Kentucky, 203 Sanders-Brown Building, 800 South Limestone Street, Lexington, KY, 40515, elizabeth.head@uky.edu.

Publisher's Disclaimer: This is a PDF file of an unedited manuscript that has been accepted for publication. As a service to our customers we are providing this early version of the manuscript. The manuscript will undergo copyediting, typesetting, and review of the resulting proof before it is published in its final citable form. Please note that during the production process errors may be discovered which could affect the content, and all legal disclaimers that apply to the journal pertain. 


\section{Keywords}

Aging; Alzheimer disease; brain; brain derived neurotrophic factor; dog; canine; cerebrovascular; immunotherapy

\section{Introduction}

Alzheimer's disease (AD) is associated with progressive cognitive decline and the accumulation of senile plaques and neurofibrillary tangles (Mirra, et al., 1991). Senile plaques contain beta-amyloid $(A \beta)$, which is a peptide thought to play a causative role in the disease (Hardy and Higgins, 1992). Several therapeutics in clinical trials are designed to reduce the production and deposition or improve clearance of $A \beta$ (Selkoe and Schenk, 2003). Immunization with fibrillar $A \beta \quad 1-42$ in mouse models of $A D$ can reduce or prevent deposition of A $\beta$ (Morgan, et al., 2000;Schenk, 1999) and improve memory (Janus, et al., 2000; Morgan, et al., 2000;Wilcock, et al., 2009; Wilcock, et al., 2004).

Clinical trials in patients with AD have led to only modest positive outcomes, or potentially serious adverse events in response to both active (A $\beta$ peptide with a conjugate to stimulate an immune response) or passive (administration of anti-A $\beta$ antibodies) (Wisniewski and Goni, 2015). Using an active vaccine, AD patients who came to autopsy showed reduced A $\beta$ (Ferrer, et al., 2004;Gilman, et al., 2005;Hock, et al., 2003;Masliah, et al., 2005;Nicoll, et al., 2003). Notably, using an active vaccine approach, decreased $A \beta$ pathology persisted 5 years after the last vaccination (Holmes, et al., 2008), although reduced brain A $\beta$ did not slow AD progression. A recent Phase 3 clinical trial using solanezumab (a humanized version of a mouse antibody $\mathrm{m} 266$ ) in a passive vaccine approach suggest benefits in those patients with mild $\mathrm{AD}$, strongly suggesting a prevention approach might be more appropriate for these therapies (Doody, et al., 2014;Karran and Hardy, 2014). Adverse effects associated with anti-A $\beta$ immunotherapy include edema and microhemorrhages in the case of passive vaccines (Sperling, et al., 2012; Wilcock and Colton, 2009) and aseptic meningoencephalitis with active vaccine approaches (Boche and Nicoll, 2008). Despite these, both are still being explored in a number of clinical trials (Wisniewski and Goni, 2015).

We have seen similar cognitive and $\mathrm{A} \beta$ outcomes to human clinical trials using an active anti-A $\beta$ immunotherapeutic approach in the canine model of human brain aging, which naturally produces human-type $\mathrm{A} \beta$ (Cotman and Head, 2008). Aged canines show a decline in memory and learning and a corresponding increase in $A \beta$ pathology (Cotman and Head, 2008). In a previous study, animals were immunized with fibrillar $A \beta 1-42$ for 2 years. Although we found little improvement in cognition, we did find evidence for maintenance of prefrontal function (reversal learning) (Head, et al., 2008). Brain A $\beta$ was significantly reduced in vaccinated animals. Based on our work with the previous canine study and the clinical trials outcomes, we hypothesized that clearing preexisting $A \beta$ was insufficient to restore neuronal function. In both dogs (Azizeh, et al., 2000;Frost, et al., 2013) and humans (Fonseca, et al., 1999;Frost, et al., 2013), A $\beta$ can be deposited over many years, which suggests neurons are chronically exposed to $A \beta$ toxicity. Thus, we introduced a second arm 
to the study, behavioral enrichment (ENR), which leads to cognitive benefits in aged canines through mechanisms independent of A $\beta$ reduction (Fahnestock, et al., 2010;Siwak-Tapp, et al., 2008). This combination approach, targeting pathways that can reduce $A \beta$ and restore neuronal function, may be more effective than either intervention alone.

We tested the hypothesis that cognitive outcomes from $A \beta$ vaccination could be improved with the addition of behavioral enrichment. Thus, a group of aged beagles were assigned to one of 4 groups: 1) control/control (C/C); (2) control/vaccine (C/V); (3) behavioral enrichment/control (E/C); (4) behavioral enrichment and vaccine (E/V). Over the duration of the study, cognition was assessed, antibody titers were measured, and cerebrospinal fluid $A \beta$ was assayed. At the end of the study, brain tissue was collected to measure $A \beta$, cerebrovascular pathology, brain derived neurotrophic factor and synaptophysin RNA levels.

\section{Materials and Methods}

\section{Animals}

As shown in Table 1, the longitudinal study started with 34 beagles (10.5 - 13.6 years Table 1): 31 from Lovelace Respiratory Research Institute (LRRI - Albuquerque, NM) and 3 from Harlan (Riglan Farms, Inc, Mount Horeb, Wisconsin). Dogs were housed in pairs $(\mathrm{n}=12)$ or singly $(\mathrm{n}=22)$ in kennel buildings with indoor/outdoor runs measuring $91 \mathrm{~cm} \mathrm{x}$ $600 \mathrm{~cm}$, which were the same kennels as used in previous studies (Head, et al., 2008; Milgram, et al., 2005). Some dogs were required to be housed singly as they were aggressive towards other dogs. However, the number of animals in each type of housing was similar across groups (Table 1). The outdoor portions of the kennels were separated by chain link fencing allowing animals to see neighboring dogs and interact. Housing conditions were randomized across treatment conditions. Dogs were fed Harlan Teklad Global Diet (25\% protein - Teklad Pioneer Lab Diets, Madison, WI) once daily and water was available at all times. All animals were thoroughly examined prior to inclusion in the study and were determined to be in good health. Examinations included physical examination, neurological examination and analysis of blood biochemistry values. All procedures were conducted in accordance with LRRI approved animal protocols and the NIH Policy on Humane Care and Use of Laboratory Animals.

\section{Overall Study Design}

The cognitive testing procedures from the previous vaccination study in dogs were repeated in the current study to allow direct comparisons between experiments (Head, et al., 2008). Dogs were first given a series of baseline cognitive tests to train them to work in the apparatus and to assess learning and memory function prior to the initiation of treatment. No food deprivation is required for any of the cognitive testing procedures as animals are motivated to acquire the food rewards. Subsequently, the vaccine and behavioral enrichment protocols were implemented. Dogs in the behavioral enrichment condition were tested throughout the treatment period as cognitive enrichment was a component of the study. In contrast, dogs provided with only the vaccine were given cognitive testing after $\sim 7$ (10 injections) and 16 (19 injections) months of follow-up to assess longitudinal cognitive 
responses. At the end of the study, the brains of all treated animals $(\mathrm{C} / \mathrm{C}, \mathrm{E} / \mathrm{C}, \mathrm{C} / \mathrm{V}, \mathrm{E} / \mathrm{V})$ were used to measure neurobiological outcomes.

\section{Baseline Cognitive Testing}

The testing apparatus has been described previously (Milgram, et al., 1994) and was a 0.609 x 1.15 x 1.08 m wooden box constructed from press board coated with melamine. The box was equipped with a sliding black Plexiglas tray containing 3 food wells. Vertical stainless steel bars, which could be adjusted to provide openings appropriate for individual dog sizes, served as the front of the box. The experimenter sat behind a barrier that is hinged to allow a sliding tray to be pushed either towards or out-of-view of the dog. A $60 \mathrm{~W}$ light was placed above the presentation tray to light the objects. Data acquisition was controlled using a customized program (MetaCog Testing Systems, New Westminster, B.C., Canada). One teaspoon (approximately $4 \mathrm{mls}$ ) of wet dog food was formed into a ball and served as the food reward. Each dog was given either 10 or 12 trials a day (depending on the task) with trials separated by a $30 \mathrm{sec}$ intertrial interval.

Dogs were tested 5 days a week. Dogs were first given an object discrimination and reversal learning task. The first test session was used to establish object preferences. On each trial, the hinged door of the barrier separating the tester and the dog was raised, and the presentation tray was pushed forward. The left and right food wells were covered by the two objects. The food reward was placed inside both the left and right food wells beneath each stimulus. Dogs were required to displace an object to obtain the hidden reward. Ten trials were given with two objects presented simultaneously (yellow plastic coffee jar lid and blue plastic Lego block) and with both objects baited. The objects appeared randomly 5 times each on the left or right side. The preferred object was whichever object was chosen more frequently (i.e. 6 or more times). Subsequently, the preferred object was used as the positive stimulus. After establishing preferences, each subject was given 10 daily trials with the food reward located beneath the designated positive object. To prevent the dogs from using olfactory cues, the food odor was smeared over both wells and a piece of food was pressed inside the negative stimulus such that the dog could smell it but not see it or eat it. A correct response was recorded when dogs approached and displaced the positive stimulus. An error was committed if dogs chose the negative object. One correction per test session was allowed and subsequent errors resulted in an immediate withdrawal of the tray leaving the dog unrewarded. Dogs were trained until one of two criterion levels was met: $9 / 10$ correct on one day or 8/10 correct on two consecutive days. An additional 3 days of testing was provided to ensure that animals maintained an average of $70 \%$ or better correct. A maximum of 400 trials were given if a dog could not reach criterion. After dogs had reached criterion in the object discrimination problem, the reward contingencies of the positive and negative stimuli were reversed. Testing was continued on this task until the same criterion as for the object discrimination test was met. All other testing procedures were identical to those used with object discrimination learning.

Following discrimination learning, dogs were given a spatial non matching to position memory task as described in our previous study (Head, et al., 2008). To assess spatial acquisition and memory, we used a 2- choice non matching to position task. Animals were 
first shown a single red Lego block covering either the left or right food wells. Animals displaced the object on one side (e.g. L) to obtain the reward. A 5-second delay interval followed, after which, animals were shown two identical red Lego blocks with the reward hidden under the object on the side not rewarded previously (e.g. R). Dogs were given 10 trials per day with a 30 second intertrial interval and were tested for 40 days. During this $40-$ day period, when criterion was met at a 5 -second delay, the delay was progressively increased to 10, 20, 30, 50, 70 and then 90 seconds. Two scores were derived from this learning phase of the task: maximal memory and total number of errors to reach criterion at the 5-second delay. Subsequently, animals were given 20 days of a variable delay problem. In this task, used to assess working memory, animals were exposed to delays of either 20, 70 or 110 seconds on each day of testing. The order of the delay interval presentation was random but each delay appeared 4 times/day and 12 trials were given each day. Accuracy scores for each delay interval were calculated as a measure of spatial working memory and used for repeated measures comparisons after treatment was started.

The total errors made for discrimination and reversal learning and for acquisition of the spatial memory task were summed and dogs were ranked according to these total error scores.

\section{A $\beta$ Vaccine}

Fibrillar A $\beta$ was prepared by adding $500 \mu$ of sterile phosphate buffered saline (PBS $\mathrm{pH}$ 7.5 ) to $0.5 \mathrm{mg}$ of peptide (provided by Dr. Charles Glabe, University of California at Irvine, Irvine, $\mathrm{CA}$ ), the sample was vortexed, and incubated overnight at $37^{\circ} \mathrm{C}$ in a water bath prior to conjugation with the adjuvant. To prepare $\mathrm{A} \beta$ for immunization, each dog received $0.5 \mathrm{mg}$ of fibrillar $\mathrm{A} \beta(500 \mu \mathrm{l})$ that was added to $50 \mu \mathrm{l}$ of $2 \%$ aluminum hydroxide (alum) suspension (Accurate Chemical, Westbury, NY) and $450 \mu$ of PBS and vortexed. All animals that did not receive fibrillar A $\beta$ 1-42 were given alum injections. Animals were immunized subcutaneously in the back of the neck and monitored for adverse reactions. After 2 weeks, animals were boosted with an additional injection followed by monthly injections thereafter. The rationale for using an active vaccine approach was twofold: (1) to use an identical vaccination approach as in our previous study to confirm and extend our results; (2) a passive vaccine approach was prohibitive in terms of the volumes required and the infusion process.

\section{Behavioral Enrichment}

Dogs in the behavioral enrichment group were given two 20-min walks outdoors in groups of 3-4 animals each week. Play toys were rotated through their kennels on a weekly basis. Cognitive enrichment involved additional testing procedures including: landmark discrimination learning ( 1 month of treatment), oddity discrimination learning (4.3 months of treatment) and a retest on landmark discrimination after $\sim 15$ months of treatment (See Table 2 - more detailed descriptions to follow). For these cognitive tasks, only dogs receiving behavioral enrichment were included. In a previous study, although the kennels were identical, behavioral enrichment also included pair housing as compared to single housing, but this was not possible in the current study given the number of animals that 
required single housing (Milgram, et al., 2005). Table 1 shows the number of animals in each group that were singly housed.

\section{Treatment Groups}

Animals were assigned to one of four treatment groups balancing for baseline cognitive test scores, sex, and age. All control animals received alum only as the injection while those receiving the active vaccine were injected with fibrillar $A \beta 1-42$ mixed with alum. These groups included 1) control/control ( $\mathrm{n}=8 ; \mathrm{C} / \mathrm{C}) ;(2)$ control/vaccine $(\mathrm{n}=8 ; \mathrm{C} / \mathrm{V}) ;(3)$ behavioral enrichment/control ( $\mathrm{n}=8 ; \mathrm{E} / \mathrm{C})$; (4) behavioral enrichment and vaccine $(\mathrm{n}=10$; $\mathrm{E} / \mathrm{V}$ ). (Table 1). The study timeline is provided in Table 2.

\section{Enrichment Task - Landmark Discrimination and Variable Landmark Test}

The landmark discrimination task and variable landmark discrimination task represent tests of spatial attention (Milgram, 1999;Milgram, et al., 2002). The first phase, Landmark 0, involved showing animals two identical objects (wooden blocks) with a third object, the landmark, placed on top of the object associated with a food reward. The correct response was to select the object associated with the landmark. Animals were trained until criterion was met, either by obtaining a score of $9 / 10$ on one day or $8 / 10$ on two consecutive days of testing. A maximum of 40 days ( 400 trials) was given for all of the landmark tasks. In the next phase of testing, the landmark was moved at successively greater distances $(1,4$ or 10 $\mathrm{cm}$ ) away from the reward object with animals required to meet criterion before progressing to testing with a larger landmark distance. Animals that could not solve the problem at any of the longer distances within 400 trials stopped testing on this stepwise protocol. Once all animals had been tested out to a $10 \mathrm{~cm}$ distance on the landmark discrimination task or had reached the maximum number of trials for a single distance, all animals were given a variable landmark distance test. In this test, animals were given 12 trials per day with the landmark being placed 1, 4 or $10 \mathrm{~cm}$ away from the correct object. These three distances appeared for 4 trials per day with 12 trials/day in total and dogs were given a total of 20 days of testing (240 trials).

Landmark discrimination learning was initiated after animals had been immunized twice (initial, 2 weeks), which was 1 month into the treatment phase of the study. In previous studies, the landmark task and the variable landmark procedure were age sensitive and improved in aged dogs with behavioral enrichment (Milgram, 1999;Milgram, et al., 2002). Following landmark discrimination learning, the variable landmark task was administered for 20 days. After 15.2 months of treatment (18 immunizations), dogs were given another 20 days of variable distance landmark testing as described previously.

\section{Enrichment Task - Oddity Discrimination}

After 4.3 months of treatment and 5 immunizations, dogs were given the next behavioral enrichment task, oddity discrimination learning, a measure of complex learning ability (Milgram, et al., 2002). In previous studies, the oddity discrimination task was age sensitive and distinguished animals receiving behavioral enrichment from controls (Cotman, et al., 2002;Milgram, et al., 2005). This task involved 4 sets of 3 objects. Two objects of each set were identical and one was novel. Animals were shown the first set and all 3 objects 
simultaneously, with a food reward hidden under the novel object. Dogs were given 12 trials per day with the location of the food reward appearing once in each of the 3 food wells each day. Once dogs learned the first problem, the next set of objects was used. The dogs were required to reach criterion levels of responding from each object set prior to moving to the more difficult object sets. Animals that failed to learn one of the oddity problems within 40 days of testing were stopped. The similarity between the odd object and the two identical object increased with each problem set such that the last problem, oddity 4 was the most difficult to discriminate.

\section{Cognitive Outcomes Across All Treatment Groups}

At pre-determined intervals, all dogs on study were administered tests of size and black/ white discrimination learning, size and black/white reversal learning and spatial memory testing (Table 2). This allowed comparison across all 4 groups to detect synergistic effects of the combined treatment. Dogs were included in each cognitive test analysis if they completed that task. If a dog had to be removed from the study, and did not complete a task, the scores were not included for that task in the data analysis.

\section{Size Discrimination and Reversal Learning}

After animals were treated for a period of 7.6 months and had received 10 immunizations, they were given a size discrimination and reversal problem. The procedures were identical to those used during baseline testing except the objects differed in size (one red wooden block vs 2 wooden blocks stacked) (Milgram, et al., 2005).

\section{Black/White Discrimination and Reversal Learning}

After animals were treated for a period of 16.1 months and had received 19 immunizations, they were given a black/white discrimination and reversal problem. The procedures were identical to those used during baseline and size discrimination testing except the objects were either a black or white lego block (Milgram, et al., 2005).

\section{Spatial Learning and Memory}

At two time points during the study, a 3-choice spatial memory task was used. The 3-choice delayed non matching to position task has been described previously (Chan, et al., 2002) and is sensitive to benefits of an antioxidant diet and behavioral enrichment with minimal practice effects (Milgram, et al., 2005). Dogs were first shown a single red Lego block covering either the left, right or center food wells. Once the object was displaced and the reward obtained, a 5-second delay interval followed. After the delay, animals were shown 2 identical red Lego blocks, one covering the well seen previously, and the other covering one of the two remaining food wells. The correct response was to select the object covering the novel food well. Dogs were given 50 days of testing with 12 trials/day with the location of the reward appearing 4 times each in the 3 food wells. During the 50 days of testing, if an animal reached criterion at the 5 -second delay, the delay was increased by 10 second increments. This was continued over the 50 days of testing with gradually increasing delay intervals. Following incremental delay interval increases over a 50-day period, dogs were given a variable delay procedure for 20 days. As with the 2-choice spatial memory task, 
dogs would be exposed to either a 20,70 , or 110 second delay in a single day of testing. Accuracy scores for each delay interval were calculated as a measure of spatial working memory. Animals were tested at two time points, the first was after 11.9 months of treatment and 14 immunizations and the second after 18.1 months of treatment and 21 immunizations.

\section{Blood and Cerebrospinal Fluid Samples}

Blood was collected from individual animals at baseline, 2 weeks, 1, 2, 3, 4, 5, 6, 12, 18 and 23 months after the first vaccination immediately prior to injections of the vaccine. Blood was collected by jugular venipuncture for both serum $(10 \mathrm{~mL})$ and plasma (10mL in EDTA). Cerebrospinal fluid (CSF) samples were taken at baseline, after 12 months of treatment, and 19.6 months of treatment immediately prior to necropsy. For CSF sampling, dogs were anesthetized with isoflurane and placed in lateral recumbency. The dorsal head and neck area was clipped and aseptically prepared, and a spinal needle was advanced into the cerebellomedullary cistern to collect approximately $1.5 \mathrm{~mL}$ of CSF.

\section{Necropsy and Brain Tissue Preparation}

At the end of the study, following blood collection, anesthesia was induced and CSF collected. Subsequently, pentobarbital-based euthanasia solution was infused intravenously. Once heart sounds could no longer be auscultated, the brain was rapidly removed. The left hemisphere was placed in $4 \%$ paraformaldehyde at $4^{\circ} \mathrm{C}$ for $72-80 \mathrm{~h}$ before transfer to PBS, $\mathrm{pH} 7.4$, with $0.02 \%$ sodium azide and stored at $4^{\circ} \mathrm{C}$. The right hemisphere was sectioned coronally and flash frozen to $-80^{\circ} \mathrm{C}$. The following subregions were dissected for each outcome measure: prefrontal cortex (PFCTX), parietal cortex (PCTX), and occipital cortex (OCTX).

\section{Serum Titers}

A $\beta$ 1-42 antibody response was measured over nine time points of the study by enzymelinked immunosorbent assay (ELISA) (Head, et al., 2008).

\section{CSF and Brain A $\beta$ ELISA}

Beta amyloid (1-40, 1-42, and total) was measured in CSF and tissue by sandwich ELISA. $A \beta$ was extracted from frozen tissue measured as previously described (Head, et al., 2010; Murphy, et al., 2010). Briefly, frozen PFCTX, PCTX) and OCTX were extracted first in PBS, then sodium dodecyl sulfate (SDS) and last, formic acid (FA). Antibodies Ab42.5 (human sequence $A \beta 1-16$ ) for $A \beta$ 1-40 capture, and 2.1.3 (end specific for $A \beta$ 1-42) were used. Biotinylated 13.1.1 (end specific for $A \beta 1-40$ ) or $4 \mathrm{G} 8$ (human sequence $A \beta$ 17-24, Covance, Dedham, MA) were used to measure total levels of $A \beta \quad 1-40$ and A $\beta$ 1-42 in CSF and in each brain fraction (PBS, SDS, and FA).

\section{A $\beta$ Plaque Load}

Tissue was stained for $A \beta$ plaques using previously published methods (Head, et al., 2008) and anti-A $\beta 42$ (Invitrogen, Carlsbad, CA; 1:500, raised against A $\beta 36-42)$, 6E10 (A $\beta 1-16$, Covance, Dedham, MA; 1:1000), and PyroGlu3 (Novus Biological, Littleton, CO; 1:500) antibodies. Tissue was pre-treated in 90\% formic acid for $4 \mathrm{~min}$ (Kitamoto, 1987). 


\section{RNA Studies}

PCTX and OCTX were available for RNA studies of the levels of brain derived neurotrophic factor. The methods have been published previously (Wilcock, et al., 2015). Briefly, frozen brain tissue was pulverized using a mortar and pestle on dry ice with liquid nitrogen, and the frozen pulverized tissue was stored at $-80^{\circ} \mathrm{C}$. RNA was extracted from approximately $80 \mathrm{mg}$ frozen pulverized tissue using the Trizol Plus RNA Purification System (Life Technologies, Grand Island NY) according to the manufacturer's instructions. RNA was quantified using the Biospec Nano spectrophotometer (Shimadzu, Columbia MD) and cDNA was reverse transcribed using the cDNA High Capacity kit (Applied Biosystems, Foster City CA) according to the manufacturer's instructions. Real-time PCR was performed using Taqman gene expression probe AB105074.1 (PMID NM_001002975.1) (Applied Biosystems, Foster City CA). Gene expression data were normalized to $18 \mathrm{~S}$ rRNA expression. Fold-change was determined using the $2^{\text {(delta delta } \mathrm{Ct})}$ method (Livak and Schmittgen, 2001).

\section{Prussian Blue Staining}

Prussian blue staining was used to identify microhemorrhages in PFCTX and OCTX tissue for all study cases using methods based on previous studies (Wilcock, et al., 2004).

\section{Image Analysis for Plaque Load and Prussian Blue Counts}

To quantify the extent of $A \beta$ plaque labeling, images were captured using ImagePro 6.3 with an Olympus Q-Color 5 camera on an Olympus BX51 microscope at 20x objective uniformly, five of the superficial layers and five of the deep layer for a total of 10 fields/ section. One section from each of the brain regions indicated for each dog was quantified in this way. Quantification was done by image analysis using ImageJ to yield load values, the percent area occupied by positive labeling similar to our previous report (Head, et al., 2008). Quantification of Prussian blue staining was by counting microhemorrhages in each tissue section using a 20X objective and counting within 10 fields/section. Prussian blue labeling within 2 cell diameters of a blood vessel was considered a microhemorrhage. Counts were totaled for each animal in each of the brain regions (Wilcock, et al., 2004).

\section{Studies in Archived Brain Tissues from Dogs for Plaque Load and Prussian Blue}

We were interested in estimating the burden of $A \beta$ pathology and microhemorrhages in our dogs prior to the start of treatment to characterize changes in pathology over time and with immunotherapy/behavioral enrichment. These dogs are referred to as the pre-treatment animals. We selected 10 dogs that ranged in age from 10.8 to 13.5 years to compare changes in plaque loads and number of microhemorrhages before treatment to 19 months of treatment in a cross-sectional approach. These pretreatment dogs had no previous treatment or cognitive testing. Tissue for the pretreatment dogs was collected and stored (in PBS with sodium azide at $4^{\circ} \mathrm{C}$ ) using the same methods as the experimental dogs.

Immunohistochemistry was used to measure total $A \beta, A \beta 42$, and PyroGlu3 plaque loads in the PFCTX and PCTX. Prussian Blue staining was used to count the number of microhemorrhages in the PFCTX and OCTX regions of the brain. All sections from the pretreatment dogs and the current study samples were run in parallel to reduce variability as a consequence of multiple immunohistochemistry experiments. 


\section{Data Analysis}

Group comparisons for each outcome measure used several approaches depending on the groups being compared and if there were repeated measures involved. ANOVA was used to compare all 4 treatment groups $(\mathrm{C} / \mathrm{C}, \mathrm{E} / \mathrm{C}, \mathrm{C} / \mathrm{V}, \mathrm{E} / \mathrm{V})$ groups on baseline cognitive test scores to ensure they were balanced with respect to error scores. T-tests were used to evaluate differences due to vaccine treatment in dogs assigned to behavioral enrichment (landmark test, oddity test) comparing the $\mathrm{E} / \mathrm{C}$ and $\mathrm{E} / \mathrm{V}$ groups. A repeated measures general linear models approach including all 4 groups was used to compare the main effects of vaccine alone, the behavioral enrichment alone, and to test the interaction (combination treatment group) for changes in $A \beta$ antibody serum titers. A generalized linear mixed model (GLMM) for a repeated measures design was used to compare repeated measures on CSF $A \beta$ and cognitive error scores among the four treatment groups corresponding to the visual discrimination and reversal tasks: object, size, and black/white. In all the analyses, cognitive error scores (both discrimination errors and reversal errors) were assumed to follow a Poisson distribution. An ANOVA was used to compare all 4 treatment groups $(\mathrm{C} / \mathrm{C}, \mathrm{E} / \mathrm{C}$, $\mathrm{C} / \mathrm{V}, \mathrm{E} / \mathrm{V})$ groups on brain $\mathrm{A} \beta$ measures. For microhemorrhage counts, we used a chi-square test to compare groups as this was a nonparametrically distributed outcome measure

While on study, 11 animals required euthanasia at different time points for medical issues unrelated to the treatments that could not be managed without discomfort. Given the age of the animals at the start of the study ( 11-12 years) and their age at the end of the study (>13 years), this is not unexpected as the median age at death of beagles in this colony is 13.2 years (i.e. 50\% of the animals are typically lost) (Lowseth, et al., 1990). Cognitive test scores were included in the analysis if they had completed the task prior to death. Only dogs that completed the study (including animals that could not be cognitively tested but maintained on treatment) were included in the neurobiological outcome measures analyses. Missing scores due to death were assumed to occur at random, while missing scores due to not learning the black-white reversal task were assigned the maximum value of given chance levels of performance (value 190 for all tasks). Statistical significance for omnibus tests was determined at the 0.05 level. Post hoc comparisons used the Bonferroni or LSD correction.

\section{Results}

At baseline, there were no significant differences between groups for scores on object discrimination learning $(F(3,33=0.56 \mathrm{p}=0.64)$ or object reversal learning $(\mathrm{F}(3,33)=0.03$ $\mathrm{p}=0.99$ ) indicating that animals were well-matched on the basis of associative learning and executive function. Spatial learning scores were equivalent across the 4 groups $(F(3,33)=0.48 \mathrm{p}=0.70)$. Spatial memory $(20 \mathrm{~s}, 70 \mathrm{~s}, 110 \mathrm{~s})$ was also evenly matched across groups at baseline with all showing a significantly reduced accuracy with increasing delays $(\mathrm{F}(2,56)=5.94 \mathrm{p}=0.005)$ but no main effects of behavioral enrichment $(\mathrm{ENR}-(\mathrm{F}(2,56)=0.19$ $\mathrm{p}=0.83)$, the vaccine $(\mathrm{VAC}-(\mathrm{F}(2,56)=1.40 \mathrm{p}=0.26)$, nor a group by delay interaction $(\mathrm{F}(2,56)=1.03 \mathrm{p}=0.37)$. 


\section{Fibrillar A $\beta$ Antibody Titers}

To determine if the anti-fibrillar $A \beta$ given to $V A C$ treated animals induced an immune response, we measured fibrillar A $\beta 1-42$ antibody titers (Figure 1A). Fibrillar $A \beta$ antibody titers significantly increased over time in VAC animals $(F(1,19)=13.6 \mathrm{p}=0.002)$. No main effect of ENR was seen on antibody titers $(F(1,19)=2.0 \mathrm{p}=0.17)$. Further, there was no interaction between the two treatments $(\mathrm{F}(1,19)=1.82 \mathrm{p}=0.19)$.

\section{Landmark Discrimination Learning}

All dogs receiving ENR were given the landmark discrimination task. A significantly higher error score was observed at the 1 month test in the dogs provided with the vaccine and behavioral enrichment (E/V) relative to the dogs receiving behavioral enrichment $(\mathrm{E} / \mathrm{C})$ alone $(\mathrm{t}(16)=2.7 \mathrm{p}=0.016)$ (data not shown). However, based on our previous research, rather than the vaccinated dogs doing more poorly, this effect was due to significantly lower error scores in all dogs, particularly in the E/C group compared to previous studies of similarly aged dogs (Milgram, et al., 2002). No other group differences were noted in landmark 1, 2 or 4 at either time point. The variable distance landmark test was conducted for a period of 20 days with 1, 2 or $4 \mathrm{~cm}$ distances appearing each day. The total number of errors made and accuracy during the 20 days of testing was not different between the $\mathrm{E} / \mathrm{V}$ and $\mathrm{E} / \mathrm{C}$ groups (data not shown).

\section{Oddity Discrimination Learning}

After 4.3 months of VAC treatment, a comparison was made between the $\mathrm{E} / \mathrm{V}$ and $\mathrm{E} / \mathrm{C}$ dogs on the oddity task. In a repeated measures analysis (4 oddity tasks) using only dogs $(n=15)$ that were able to reach criterion levels of responding on all tasks there was a significant main effect of the task $(\mathrm{F}(3,39)=4.75 \mathrm{p}=0.006)$ suggesting increasing difficulty as was intended, but no treatment group by oddity task interaction $(\mathrm{F}(3,39)=0.39 \mathrm{p}=0.76)$. Overall there were no treatment group differences $(\mathrm{F}(1,13)=3.41 \mathrm{p}=0.088)$ (data not shown).

\section{Repeated Visual Discrimination and Reversal Learning}

To detect any treatment effects over time, a possible maintenance of function, and a synergistic effect of the ENR on VAC, we compared baseline object discrimination to size discrimination (7.6 months of treatment) and to black/white discrimination (16.1 months of treatment) only in animals able to reach criterion for all 3 tasks (Figure 1B). Discrimination learning errors over time showed a highly significant treatment group by time interaction ( $\mathrm{P}$ $<0.0001)$. Post hoc comparison of the treatment effects shows that for each treatment group the three tasks differ from one another. For object and size discrimination, there was no significant difference among the 4 groups. For the black/white discrimination task, the effect of time for the combination group $(\mathrm{E} / \mathrm{V})$ is significantly smaller than the effects for $\mathrm{C} / \mathrm{C}$ and $\mathrm{C} / \mathrm{V}$ groups ( $\mathrm{P}=0.03$ for each comparison) but only marginally smaller than the effect for $\mathrm{E} / \mathrm{C}(\mathrm{P}=0.054)$. The results of treatment on discrimination learning over time indicate that the combination treatment group shows a synergistic maintenance of cognition over time.

Errors on the repeated reversal tasks revealed a highly significant treatment group by time interaction with means at baseline being 11.12 errors, to size reversal with 33.2 errors and then black/white discrimination with 32.3 errors $(\mathrm{P}<0.0001)$ (Figure 1C). For the black/ 
white reversal task the $\mathrm{E} / \mathrm{C}$ group differs from the other three groups while the $\mathrm{C} / \mathrm{V}$ group also differs from $\mathrm{E} / \mathrm{V}$ and $\mathrm{C} / \mathrm{C}$, which do not differ from one another. These results suggest that there was impairment in reversal learning in the dogs receiving the vaccine alone, which was ameliorated with the addition of behavioral enrichment. Further, the dogs receiving the behavioral enrichment alone had the lowest average error scores.

\section{Spatial Acquisition and Memory}

Once dogs had been treated for 11.9 months or for 18.1 months (Table 2), they were tested on the 3-choice spatial memory task where the delays of 20,70 or 110 seconds could occur on a single day. Only dogs that were able to complete all the testing across the 2 time points were included in the analysis. Neither treatment alone or when combined resulted in improved spatial memory. To detect any changes in spatial memory as a function of treatment over the 18 months of the study, a repeated measures analysis was used for each delay interval separately $(20,70,110 \mathrm{~s})$. At the 20 second delay $(F(2,36)=16.12 \mathrm{p}<0.0005)$, the 70 second delay $(\mathrm{F}(2,36)=5.51 \mathrm{p}=0.008)$ and the 110 second delay $(\mathrm{F}(2,36)=17.32$ $\mathrm{p}<0.0005)$ there was an overall decrease in accuracy over time suggesting an aging effect. There was no apparent maintenance of spatial memory over time as a function of treatment or an effect of the combined treatment (data not shown).

\section{CSF A $\beta$}

For CSF A $\beta$ outcome measures, only animals that completed over 18 months of the treatment protocol and where CSF samples were acquired at every time point were included $(\mathrm{n}=21 ; \mathrm{C} / \mathrm{C}-7, \mathrm{E} / \mathrm{C}-4, \mathrm{C} / \mathrm{V}-5, \mathrm{E} / \mathrm{V}-5)$. None of the effects in the linear mixed model (LMM) for CSF A $\beta 40$, namely, the main effect due to VAC or ENR, the interaction between VAC and ENR, the main effect due to time, and the interactions between time and VAC, time and ENR, or time, VAC and ENR are significant ( $\mathrm{P}>0.11$ for each effect).

However, for CSF A 42 (Figure 2A) there is a significant main effect due to the VAC ( $\mathrm{P}=$ 0.01 ) in that the adjusted mean CSF $A \beta 42$ level in the presence of VAC is $134.4 \mathrm{pmol} \pm 7.1$, which is higher than CSF A $\beta 42$ measures in the absence of the VAC (104.7 \pm 7.6$)$. None of the other effects in the LMM are significant $(\mathrm{P}>0.12)$ although there is a hint of an interaction between VAC and ENR. The increased CSF A $\beta 42$ VAC effect appears to be associated with the presence of ENR (ENR with no VAC at $92.9 \pm 12.5$ and with VAC at $139.8 \pm 9.8$ ). This is in contrast to CSF $A \beta 42$ in groups with no VAC at $116.5 \pm 8.7$ versus those with the VAC at $129.0 \pm 10.3$ in the absence of ENR, indicating a much smaller VAC effect $(\mathrm{P}=0.12$ for the interaction between ENR and VAC).

\section{Brain $A \beta$}

We hypothesized that the levels of $A \beta 1-40$ and $A \beta \quad 1-42$ in the brain would be reduced due to the vaccine as we reported previously (Head, et al., 2008) and possibly further reduced with the presence of behavioral enrichment. As a first test of this hypothesis we measured the extent of plaques containing $A \beta 42$, total $A \beta$ (using $6 E 10 A \beta 1-16$ ), and pyroglutamate $\mathrm{A} \beta$ in the PFCTX, PCTX and OCTX by immunohistochemistry. For these analyses we used an ANOVA with a 2 x 2 factorial design with factors VAC (yes/no) and ENR (yes/no) to compare mean responses. 
$\mathrm{A} \beta 42$ plaque load was significantly decreased as a result of VAC (both $\mathrm{C} / \mathrm{V}$ and $\mathrm{E} / \mathrm{V}$ groups) in the PFCTX $(\mathrm{p}<0.01)$, OCTX ( $\mathrm{p}=0.01)$, and PCTX ( $\mathrm{p}=0.03$ ) (Figure 2B). No additive effects were seen between the VAC and ENR in reducing $A \beta 42$ plaque load in any brain region sampled. Representative examples of immunolabeling in the prefrontal cortex for each treatment group are shown in Figures $2 \mathrm{E}-\mathrm{H}$. Total $\mathrm{A} \beta$ (6E10) plaque load was reduced by the VAC in all brain regions (PFCTX, $\mathrm{p}<0.01$; OCTX, $\mathrm{p}=0.03$; PCTX, $\mathrm{p}=0.04$ ) (Figure $2 \mathrm{C})$. No additive effects were detected in the combination treatment group in decreasing total $A \beta$ plaque loads in any of the brain regions sampled. Previous immunotherapy studies have not evaluated effects of an anti-fibrillar $A \beta 1-42$ vaccine on post-translationally modified $A \beta$. Since post-translationally modified $A \beta$, more specifically $A \beta p E 3$, is considered to be a more toxic and chronobiologically older form of $A \beta$, we tested our vaccine on its ability to reduce this form of $A \beta$. We hypothesized that VAC would significantly reduce $\mathrm{A} \beta \mathrm{pE} 3$ plaque loads in all regions examined. $\mathrm{A} \beta \mathrm{pE} 3$ plaque loads were decreased only in PFCTX ( $\mathrm{p}=0.01$ ) but not PCTX or OCTX (Figure 2D). No main effects of the ENR or an ENR by VAC interaction were observed.

As a second test of this hypothesis and to confirm reductions in $A \beta$ plaque loads, we measured PBS, SDS, and FA extracted A $\beta \quad 1-40$ and A $\beta$ 1-42 by sandwich ELISA (Figure 3 ). For these analyses we used an ANOVA with a $2 \times 2$ factorial design with factors VAC (yes/no) and ENR (yes/no) to compare mean responses. There was a significant amount of individual variability in the amounts of $A \beta$ measured and no treatment effects were observed for either $\mathrm{A} \beta 40$ (Figure 3A) or $\mathrm{A} \beta 42$ (Figure 3D) extracted from the PBS soluble fraction. In SDS extracted A $\beta 42$ (Figure 3B), there was a significant main effect of the VAC with reduced levels in the PFCTX and OCTX ( $p<.05)$ but not in A $\beta 40$ (Figure 3E). FA extracted A $\beta 42$ (Figure 3C) was decreased in the PFCTX, PCTX and OCTX consistent with plaque load outcomes; FA extracted A $\beta 40(\mathrm{p}=0.01)$ in the PFCTX and $\mathrm{A} \beta 42(\mathrm{p}=0.01)$ extracted from PFCTX, PCTX and OCTX was decreased in VAC dogs but not ENR dogs and there was no interaction between the two treatments. The OCTX also showed evidence of reduced FA extracted $\mathrm{A} \beta 42$ in the ENR group ( $\mathrm{p}=0.01$ ), the VAC group ( $\mathrm{p}=0.02$ ) as well as an interaction with in the combination group $(\mathrm{p}=0.03)$. This interaction effect appears to result in less of an $\mathrm{A} \beta 42$ reduction for combination treatment group animals relative to dogs provided with the VAC alone.

\section{Comparison of A $\beta$ Plaque Loads of Study Dogs to Pretreatment Brains}

The PFCTX had lower A $\beta 42$ plaque loads due to ENR that trended towards significance. In addition, although no ENR effect was seen statistically in lowering total $A \beta$ plaque loads in the PFCTX and PCTX, the E/C treatment group did have significantly lower loads than the $\mathrm{C} / \mathrm{C}$ group. It is unclear if these lower plaque loads were due to a clearance of pre-existing $A \beta$ or maintenance of $A \beta$ pathology at the same level that was present at the start of treatment by the ENR. To investigate this further, we used PFCTX and PCTX tissue of archive cases that were age-matched to study cases at their baseline age and immunostained them for $A \beta 42$ (10/10 animals were positive based on a cut off of $1 \%$ load), total $A \beta(10 / 10$ positive) and $A \beta p E 3$ ( $1 / 10$ positive). The results provided measurements that represented the $\mathrm{A} \beta$ plaque loads of the study cases at baseline before treatment began. The $\mathrm{A} \beta$ loads obtained from this archival group are also shown in Figure 2B, C and D. 
In the PFCTX, significant group effects were seen in the reduction of $A \beta 42(p<0.001)$, total $\mathrm{A} \beta(\mathrm{p}<0.001)$, and $\mathrm{A} \beta \mathrm{pE} 3(\mathrm{p}=0.009)$ plaque loads between the pre-treatment group to the study treatment groups. The pre-treatment group had significantly lower $A \beta 42(p=0.050)$ and total $\mathrm{A} \beta(\mathrm{p}=0.014)$ plaque loads than the $\mathrm{C} / \mathrm{C}$ group indicating an increase in plaque loads with age. The plaque loads of the pre-treatment group did not statistically differ from the E/C group, suggesting a maintenance effect due to the ENR ( $p<.05)$. Similar results were observed in the PCTX. A significant group difference was noted when comparing A $\beta 42$ $(\mathrm{p}=0.003)$, total $\mathrm{A} \beta(\mathrm{p}=0.021)$, and $\mathrm{A} \beta \mathrm{pE} 3(\mathrm{p}=0.020)$ plaque loads between the pretreatment group to the study treatment groups in the PCTX (Figures 2B,C,D). As seen in the PFCTX, the pre-treatment group $A \beta 42$ plaque load did not differ significantly from the $\mathrm{E} / \mathrm{C}$ group in the PCTX, again suggesting that ENR was likely maintaining A $\beta 42$ plaque loads at levels that were in the brain 2 years prior.

\section{Treatment Effects on Microhemorrhages}

Based on previous studies in transgenic mice (Pfeifer, et al., 2002;Racke, et al., 2005;Wilcock and Colton, 2009; Wilcock, et al., 2007;Wilcock, et al., 2004) and human clinical trials (Uro-Coste, et al., 2010), we hypothesized that the two VAC groups may have more microhemorrhages than those animals receiving no VAC. The total number of bleeds across all brain regions sampled ranged between 0 and 23 and we used a Kruskal-Wallis test to compare the groups. The most bleeds were seen in the PFCTX having a range from 1 to 10 bleeds, with the exception of one dog having 17 bleeds (representative examples are provided in Figure 4B, C, D). This canine in particular was a female, started the study at the age of 11.6 years, and was in the E/C treatment group. The OCTX had bleed counts ranging from 0 to 7. Neither ENR $(H(1)=0.025 p=0.876)$ nor $\operatorname{VAC}(H(1)=0.350 p=0.554)$ significantly increased microhemorrhage frequency in the PFCTX (Figure 4A). In the OCTX, there was a statistically significant overall increase in microhemorrhages due to the $\operatorname{VAC}(H(1)=6.501 \mathrm{p}=0.011)(\mathrm{C} / \mathrm{V}$ and $\mathrm{E} / \mathrm{V}$ groups - Figure 4A,D). Interestingly, fewer microhemorrhages were detected in the $\mathrm{E} / \mathrm{C}$ animals in the OCTX compared to $\mathrm{C} / \mathrm{V}$ animals (Figure 4A). It is possible that this decrease in microhemorrhages of the E/C group (non VAC animals) could have led to the statistically apparently higher frequency of microhemorrhages due to the VAC.

With the observation that E/C group had fewer microhemorrhages in the OCTX compared to the other treatment groups and $\mathrm{C} / \mathrm{C}$ group, we wanted to determine whether ENR was reducing the number of microhemorrhages or having a maintenance effect as observed with plaque loads. To do this we used the same 10 archive cases used for plaque load analysis that were age-matched to study dogs at the start of the study (10.5-13.6 years) (pre-treatment). The total number of microhemorrhages in the PFCTX from this pre-treatment group of dogs ranged from one to eight, similar to numbers in the treatment groups and control group. Statistically, there was no group difference in microhemorrhage counts in the PFCTX between the pre-treatment group and the four study groups $\left(\chi^{2}(4)=1.103 p=0.894\right)$ (Figure $4 \mathrm{~A})$. In the OCTX, pre-treatment dogs only showed 0 to 3 microhemorrhages compared to the 0 to 7 range seen in the study dogs. There were significantly different microhemorrhage counts between the groups (the four study groups ${ }^{2}(4)=15.400 \mathrm{p}=0.004$ ). The pre-treatment group showed approximately the same number of microhemorrhages as the E/C treatment 
group (Figure 4A). While the $\mathrm{C} / \mathrm{C}, \mathrm{C} / \mathrm{V}$, and $\mathrm{E} / \mathrm{V}$ treatment groups were not different in number of microhemorrhages, they generally were higher than the pre-treatment and $\mathrm{E} / \mathrm{C}$ groups. This would suggest that the $\mathrm{E} / \mathrm{C}$ treatment was having a maintenance or protective effect against microhemorrhages in the OCTX while all other treatment groups experienced more microhemorrhages with age independently of the VAC.

\section{Brain derived neurotrophic factor as a function of treatment}

We next tested the hypothesis that brain derived neurotrophic factor (BDNF) RNA levels would be increased in dogs provided with ENR and possibly further increased when combined with $\mathrm{A} \beta$ clearance with the vaccine. Figure 5 shows that relative to the $\mathrm{C} / \mathrm{C}$ group, the parietal cortex of the $\mathrm{C} / \mathrm{V}$ group had increased BDNF mRNA ( $\sim 1.4$ fold) that were not significant but the combination treatment $(\mathrm{E} / \mathrm{V})$ was associated with a significant increase in BDNF mRNA level (1.6 fold). The E/C group was not different from the CC group ( 0.7 fold). No systematic differences in the occipital cortex were observed in BDNF mRNA level (data not shown).

\section{Discussion}

The current study hypothesized that aged dogs with pre-existing $A \beta$ pathology vaccinated with fibrillar $A \beta 1-42$ would show reduced $A \beta$ neuropathology as observed previously, but also improved cognition if the vaccine was combined with behavioral enrichment.

Consistent with previous studies in aged dogs, the active $A \beta$ vaccine alone did not improve cognition (Head, et al., 2008). As hypothesized, dogs in the combination treatment group showed a slowing in cognitive decline on a measure of visual discrimination learning. The addition of ENR on the vaccine was particularly striking on a measure of executive function (reversal learning). We observed impaired function in dogs provided with the VAC alone that was significantly improved with the addition of ENR. Brain A $\beta$ was reduced with the VAC in the current study similar to our previous report (Head, et al., 2008). BDNF mRNA levels were increased significantly in dogs provided with the combination treatment, providing a possible mechanism underlying cognitive improvements and similar to a previous study of the combination effects of behavioral enrichment with an antioxidant diet (Fahnestock, et al., 2010). Interestingly, there were several unexpected findings in the current study. First, ENR resulted in less brain $A \beta$ on a subset of the brain regions sampled, consistent with some but not all AD mouse model studies (Lazarov, et al., 2005) but novel with respect to canines (Pop, et al., 2010). Second, ENR may slow cerebrovascular pathology in aging dogs, which may have significant clinical implications for trials testing immunotherapy in patients with AD. A summary of the outcome measures are provided in Table 3.

\section{Effects of the VAC on aging dogs}

Cognition-We had previously published the results of an $A \beta$ vaccine in aging dogs showing no improvements in learning and memory, but evidence of a maintenance of function on an executive function task (reversal learning) (Head, et al., 2008). We observed some similar and yet interesting differences in the current study. There was no evidence of an improvement in learning or memory in VAC dogs, similar to our previous report (Head, et al., 2008). This contrasts with another study of pet dogs (6-18 years, differing breeds) with 
cognitive dysfunction syndrome that showed rapid improvements in cognition in response to active $A \beta$ immunotherapy (Bosch, et al., 2013). It is interesting that in the Bosch et al., study that the authors used $A \beta 40$ or $A \beta x-40$ peptides as the immunogen in contrast to the current study using fibrillar $A \beta 1-42$. Despite these differing approaches, the mechanism underlying rapid cognitive improvements in one study and slower decline in the current study have yet to be determined.

We also found that dogs receiving the VAC alone showed impaired executive function that evolved after 16 months of treatment. Interestingly, this was ameliorated with the presence of ENR as will be discussed shortly. This was unexpected given our previous work showing that the same vaccine slowed reversal learning deficits over time (Head, et al., 2008). When comparing the two studies, dogs in our previous study were between 9.3 and 9.5 years of age when treatment was initiated, whereas in the current study, dogs were 11.5 to 11.9 years of age. Thus, an earlier intervention resulted in benefits to executive function that could not be elicited in the older animals unless combined with behavioral enrichment.

A $\beta$ Neuropathology-Active $A \beta$ vaccination and passive immunotherapy studies show positive results in reducing $A \beta$ plaque pathology in both animal models and patients with AD (DeMattos, et al., 2001;Head, et al., 2008;Release, 2012;Salloway, et al., 2014;Salloway, et al., 2009;Schenk, et al., 1999;Silverman, 2012;Teich, 2012). VAC in dogs reduces brain $A \beta 42$ measured by plaque load and both $A \beta 40$ and $A \beta 42$ measured biochemically in the insoluble FA fraction as reported previously (Head, et al., 2008). These results are also similar to another report of immunotherapy with $A \beta$ in dogs showing reduced $A \beta$ plaque pathology (Neus Bosch, et al., 2015). Novel outcomes of the current study indicate first, that PBS soluble $A \beta$ in the brain was not reduced, suggesting the VAC did not change $A \beta$ production per se. SDS soluble $A \beta 42$ was reduced in response to the VAC but not $\mathrm{A} \beta 40$. Post-translationally modified $\mathrm{A} \beta$, including $\mathrm{A} \beta \mathrm{pE} 3$, is toxic and involved in the initial stages of the disease thereby making it a crucial therapeutic target for clearance in a clinical setting (Alexandru, et al., 2011;He and Barrow, 1999;Russo, et al., 2002;Schilling, et al., 2006; Schlenzig, et al., 2009; Wirths, et al., 2009). In the current study, A $\beta$ pE3 was cleared in VAC dogs, particularly in the prefrontal cortex. This outcome is promising for human clinical trials given that a significant amount of $A \beta$ is post translationally modified and thought to be highly aggregated and less amenable to clearance in dog (Azizeh, et al., 2000; Chambers, et al., 2011;Frost, et al., 2013;Schmidt, et al., 2015) and human brain (Azizeh, et al., 2000;Fonseca, et al., 1999;Frost, et al., 2013). Last, CSF A 342 was increased in dogs receiving the VAC suggesting clearance from the brain parenchyma that could be detected peripherally. An inverse correlation between CSF and brain A $\beta$ has been reported in humans (Blennow, et al., 2015;Strozyk, et al., 2003) and dogs (Head, et al., 2010) suggesting that as brain A $\beta$ deposits it is depleted from the CSF (DeMattos, et al., 2002). Thus, CSF levels of A $\beta 42$ may serve as a useful noninvasive outcome measure to detect beneficial effects of immunotherapy on brain $A \beta$.

Microhemorrhages-Because previous human clinical trials using active vaccination with fibrillar $A \beta_{1-42}$ was associated with several cases of meningoencephalitis (Gilman, et al., 2005; Hock, et al., 2003), passive immunization is currently being investigated in mild to 
moderate AD. This passive immunotherapy approach also reduces $\mathrm{A} \beta$ pathology and leads to modest reductions in rates of cognitive decline (Doody, et al., 2014;Doody, et al., 2014; Salloway, et al., 2014;Salloway, et al., 2014). Passive immunotherapies, however, lead to microhemorrhages in mouse models (Wilcock, et al., 2004) and in human clinical trials (Sperling, et al., 2012). The presence of microhemorrhages could increase risk of further cognitive impairment (Blitstein and Tung, 2007; Viswanathan and Chabriat, 2006). Thus, we also measured the extent of microhemorrhages in VAC animals and noted an increase in microhemorrhages in the occipital cortex, but not prefrontal cortex suggesting canines can provide a useful model to detect adverse outcomes in response to immunotherapy.

\section{Effects of ENR on aging dogs}

Cognition-Dogs provided with ENR in our previous studies showed improved cognition(Milgram, et al., 2002), maintenance of cognition and improved memory (Cotman, et al., 2002;Milgram, et al., 2005). However, ENR dogs we described previously did not show reduced brain $A \beta$ suggesting that the mechanism of action was independent of $A \beta$ deposition (Pop, et al., 2010). Interestingly, we did not observe similar outcomes in the current study: ENR dogs did not show improved cognition, nor maintenance of cognition. This outcome was unexpected as our previous research suggested that ENR was a robust means to improve cognitive function in dogs (Costa, et al., 2006;Cotman and Head, 2008; Lazarov, et al., 2005). The reasons for this may be two-fold. First, dogs in the previous study were younger when treatment was started and as such, may have been more responsive to the enrichment protocol whereas the older animals in the current study did not show the same benefits. Second, standard housing-enrichment programs have matured from earlier studies such that an ENR threshold may have been met between all treatment groups and further benefits did not occur with the additional environmental enrichment and cognitive training that was provided in this study. It is possible the lack of consistent pair housing as compared to single housing used previously may have led to larger cognitive benefits than observed here (Milgram, et al., 2005). Alternatively, our previous study may have revealed that singly housed dogs were impoverished relative to the pair housed animals. A more intensive program may be required for future treatment studies.

A $\beta$ Neuropathology-Novel findings in the current study relate to the effects of ENR on $A \beta$ deposition. In our previous ENR study in canines we did not observe a reduction in $A \beta$ pathology after over 2 years of treatment (Pop, et al., 2010). However, in the current study, we observed ENR led to reduced total $A \beta$ plaque loads, similar to previous reports in transgenic mouse models of AD (Costa, et al., 2006;Lazarov, et al., 2005). Reduced plaque loads in response to ENR in the current study may indicate a prevention benefit. Lower plaque loads in ENR animals may be due to a slowing of $A \beta$ accumulation. Tissue samples from dogs that were the same age as animals at the start of the study allowed us to estimate the extent of $A \beta$ at baseline. The pre-treatment dogs exhibited significantly lower plaque loads than control dogs for all types of $A \beta$ examined illustrating the increase of plaque loads in the canine with age over the $\sim 2$ year period of time. Further, the pre-treatment dog A $\beta$ plaque pathology most closely resembled that of the E/C treatment group suggesting that ENR led to maintenance of plaque load in treated dogs rather than a clearance/reduction of existing $\mathrm{A} \beta$ plaques. The results of the studies with $\mathrm{A} \beta \mathrm{pE} 3$ confirm and extend this 
interpretation. $\mathrm{A} \beta \mathrm{pE} 3$ plaque loads were not reduced in dogs that received ENR suggesting that pre-existing plaque pathology was not cleared, in contrast to the VAC dogs. The mechanism by which $A \beta$ is reduced in dogs provided with ENR has yet to be explored but previous studies argue against changes in alpha-secretase activity and total APP (Pop, et al., 2010).

Microhemorrhages-As described previously, microhemorrhage frequency was increased in the occipital cortex due to the VAC. However, the ENR dogs had a significantly lower number of microhemorrhages. By comparing ENR (E/C) animals to pre-treatment brain samples, we found that dogs that were 2 years younger showed a similar number of microhemorrhages in the OCTX as the E/C treatment group. This observation suggests that ENR may protect from age-associated increases in microhemorrhages. Similar cerebrovascular benefits have been reported in transgenic mouse models of $\mathrm{AD}$ (Herring, et al., 2008).

\section{Synergist Effects of Combining ENR with VAC}

The overarching goal of the study was to test the hypothesis that the combination of ENR and VAC would lead to cognitive benefits and reduced brain pathology. To some extent, our hypothesis was supported and yet in other aspects, refuted. As expected, dogs receiving the VAC developed anti-A $\beta 1-42$ titers over time.

In terms of cognitive outcomes, the results were modest. We observed that dogs receiving the combination treatment showed a significant maintenance of learning on a series of visual discrimination tasks that was larger than either ENR or VAC alone. The ENR also appears to ameliorate executive dysfunction in VAC only treated dogs although it cannot improve dogs to levels observed in the ENR condition alone. However, none of the treatments improved memory. The combination treatment group showed significantly reduced prefrontal, and parietal and in some cases occipital $\mathrm{A} \beta$ in terms of plaque loads, posttranslationally modified $A \beta$, and insoluble $A \beta$ although not lower than the VAC alone. Given that the VAC essentially cleared $A \beta$ plaques, it is not surprising we could not detect further reductions. However, the benefits of ENR on reducing microhemorrhages could not be observed with the combination treatment suggesting that the VAC drives this pathology to a greater extent than ENR counteracting the effect. The implications of our observation of increased numbers of microhemorrhages in the VAC group are that the response of aging dogs to the vaccine is similar (and possibly predictive) of human clinical trials outcomes and also suggests a common pathological mechanism.

Another novel outcome to the current study involved the measures of BDNF mRNA. BDNF is a critical growth factor supporting neuron and synapse health (Ando, 2002;Lu, et al., 2008), and is reduced in AD transgenic mice and in human AD brain (Holsinger, et al., 2000;Intlekofer and Cotman, 2013;Michalski and Fahnestock, 2003;Poon, et al., 2011). BDNF levels can be increased in by physical activity (Cotman, et al., 2007;Intlekofer and Cotman, 2013) and by environmental enrichment (Wolf, et al., 2006;Zajac, et al., 2010). In dogs, aging is associated with significantly reduced BDNF mRNA in temporal cortex that can be improved when animals are provided with a combination of behavioral enrichment 
and an antioxidant diet (Fahnestock, et al., 2010). To determine if downstream pathologies associated with $A \beta$ may be modified with behavioral enrichment or in vaccinated dogs, we measured RNA levels of BDNF. In the current study we found that BDNF mRNA was increased in vaccinated dogs and significantly increased in the combination group. Thus, reducing $\mathrm{A} \beta$ may be linked to increased BDNF and may in part, be associated with the cognitive maintenance observed in the current study.

\section{Conclusions}

Behavioral enrichment slows $A \beta$ accumulation and reduces the rate of microhemorrhages, while an $A \beta$ vaccine clears pre-existing $A \beta$ pathology including post-translationally modified $\mathrm{A} \beta$.The combination treatment maintained visual discrimination learning over $\sim 19$ months suggesting a slowing of cognitive decline. Several clinical trials are underway that are assessing lifestyle modifications including exercise and cognitive training in nondemented elderly (for a review see (Solomon, et al., 2014)). Aged canines may represent an early AD phenotype (Cotman and Head, 2008) that is associated with selective hippocampal neuron losses (Siwak-Tapp, et al., 2008). The combination treatment approach described in this experiment may be more efficacious if implemented prior to significant cognitive decline and $\mathrm{A} \beta$ deposition that occurs in dogs beginning around $6-8$ years (Cotman and Head, 2008). However, it is exciting to note that even in animals with extensive $\mathrm{A} \beta$ deposition and cognitive dysfunction that benefits could be elicited, which is promising for patients with mild-moderate AD. In the future, prevention studies using a combination therapy approach in middle aged dogs may result in memory maintenance, and including imaging techniques that enable us to visualize cerebrovascular benefits will be helpful.

\section{Acknowledgments}

Research reported in this manuscript was supported by National Institutes on Health, National Institutes on Aging Grant R01AG032550 to EH. The project described was also supported by the National Center for Advancing Translational Sciences, UL1TR000117 to PRD. We thank Dr. Charles Glabe, University of California at Irvine for providing the A $\beta$ peptide. We also appreciate the assistance from Valerie Ward and Dylan Armes at Lovelace Respiratory Research Institute during the cognitive testing portion of the study. The content is solely the responsibility of the authors and does not necessarily represent the official views of the National Institutes of Health. The authors appreciate the editorial assistance from Paula Thomason.

\section{References Cited}

Alexandru A, Jagla W, Graubner S, Becker A, Bauscher C, Kohlmann S, Sedlmeier R, Raber KA, Cynis H, Ronicke R, Reymann KG, Petrasch-Parwez E, Hartlage-Rubsamen M, Waniek A, Rossner S, Schilling S, Osmand AP, Demuth HU, von Horsten S. Selective hippocampal neurodegeneration in transgenic mice expressing small amounts of truncated Abeta is induced by pyroglutamate-Abeta formation. J Neurosci. 2011; 31(36):12790-801. [PubMed: 21900558]

Ando S, Kobayashi S, Waki H, Kon K, Fukui F, Tadenuma T, Iwamoto M, Takeda Y, Izumiyama N, Watanabe K, Nakamura H. Animal model of dementia induced by entorhinal synaptic damage and partial restoration of cognitive deficits by BDNF and carnitine. J Neurosci Res. 2002; 70:519-27. [PubMed: 12391613]

Azizeh BY, Head E, Ibrahim MA, Torp R, Tenner AJ, Kim RC, Lott IT, Cotman CW. Molecular dating of senile plaques in the brains of individuals with Down syndrome and in aged dogs. Exp Neurol. 2000; 163(1):111-22. [PubMed: 10785449]

Blennow K, Mattsson N, Scholl M, Hansson O, Zetterberg H. Amyloid biomarkers in Alzheimer's disease. Trends Pharmacol Sci. 2015; 36(5):297-309. [PubMed: 25840462] 
Blitstein MK, Tung GA. MRI of cerebral microhemorrhages. AJR American journal of roentgenology. 2007; 189(3):720-5. [PubMed: 17715122]

Boche D, Nicoll JA. The role of the immune system in clearance of abeta from the brain. Brain Pathol. 2008; 18(2):267-78. [PubMed: 18363937]

Bosch MN, Gimeno-Bayon J, Rodriguez MJ, Pugliese M, Mahy N. Rapid improvement of canine cognitive dysfunction with immunotherapy designed for Alzheimer's disease. Curr Alzheimer Res. 2013; 10(5):482-93. [PubMed: 23566345]

Chambers JK, Mutsuga M, Uchida K, Nakayama H. Characterization of AbetapN3 deposition in the brains of dogs of various ages and other animal species. Amyloid. 2011; 18(2):63-71. [PubMed: 21557687]

Chan AD, Nippak PM, Murphey H, Ikeda-Douglas CJ, Muggenburg B, Head E, Cotman CW, Milgram NW. Visuospatial impairments in aged canines (Canis familiaris): the role of cognitive-behavioral flexibility. Behav Neurosci. 2002; 116(3):443-54. [PubMed: 12049325]

Costa DA, Cracchiolo JR, Bachstetter AD, Hughes TF, Bales KR, Paul SM, Mervis RF, Arendash GW, Potter H. Enrichment improves cognition in $\mathrm{AD}$ mice by amyloid-related and unrelated mechanisms. Neurobiol Aging. 2006

Cotman CW, Berchtold NC, Christie LA. Exercise builds brain health: key roles of growth factor cascades and inflammation. Trends Neurosci. 2007; 30(9):464-72. [PubMed: 17765329]

Cotman CW, Head E. The canine (dog) model of human aging and disease: dietary, environmental and immunotherapy approaches. J Alzheimers Dis. 2008; 15(4):685-707. [PubMed: 19096165]

Cotman CW, Head E, Muggenburg BA, Zicker S, Milgram NW. Brain Aging in the Canine: A Diet Enriched in Antioxidants Reduces Cognitive Dysfunction. Neurobiology of Aging. 2002; 23(5): 809-18. [PubMed: 12392784]

DeMattos RB, Bales KR, Cummins DJ, Dodart JC, Paul SM, Holtzman DM. Peripheral anti-A beta antibody alters CNS and plasma A beta clearance and decreases brain A beta burden in a mouse model of Alzheimer's disease. Proc Natl Acad Sci U S A. 2001; 98(15):8850-5. [PubMed: 11438712]

DeMattos RB, Bales KR, Cummins DJ, Paul SM, Holtzman DM. Brain to plasma amyloid-beta efflux: a measure of brain amyloid burden in a mouse model of Alzheimer's disease. Science. 2002; 295(5563):2264-7. [PubMed: 11910111]

Doody RS, Farlow M, Aisen PS. Phase 3 trials of solanezumab and bapineuzumab for Alzheimer's disease. N Engl J Med. 2014; 370(15):1460.

Doody RS, Thomas RG, Farlow M, Iwatsubo T, Vellas B, Joffe S, Kieburtz K, Raman R, Sun X, Aisen PS, Siemers E, Liu-Seifert H, Mohs R. Alzheimer's Disease Cooperative Study Steering C, Solanezumab Study G. Phase 3 trials of solanezumab for mild-to-moderate Alzheimer's disease. N Engl J Med. 2014; 370(4):311-21. [PubMed: 24450890]

Fahnestock M, Marchese M, Head E, Pop V, Michalski B, Milgram WN, Cotman CW. BDNF increases with behavioral enrichment and an antioxidant diet in the aged dog. Neurobiol Aging. 2010

Ferrer I, Boada Rovira M, Sanchez Guerra ML, Rey MJ, Costa-Jussa F. Neuropathology and pathogenesis of encephalitis following amyloid-beta immunization in Alzheimer's disease. Brain Pathol. 2004; 14(1):11-20. [PubMed: 14997933]

Fonseca MI, Head E, Velazquez P, Cotman CW, Tenner AJ. The presence of isoaspartic acid in betaamyloid plaques indicates plaque age. Exp Neurol. 1999; 157(2):277-88. [PubMed: 10364440]

Frost JL, Le KX, Cynis H, Ekpo E, Kleinschmidt M, Palmour RM, Ervin FR, Snigdha S, Cotman CW, Saido TC, Vassar RJ, St George-Hyslop P, Ikezu T, Schilling S, Demuth HU, Lemere CA. Pyroglutamate-3 amyloid-beta deposition in the brains of humans, non-human primates, canines, and Alzheimer disease-like transgenic mouse models. Am J Pathol. 2013; 183(2):369-81. [PubMed: 23747948]

Gilman S, Koller M, Black RS, Jenkins L, Griffith SG, Fox NC, Eisner L, Kirby L, Rovira MB, Forette F, Orgogozo JM. Clinical effects of Abeta immunization (AN1792) in patients with AD in an interrupted trial. Neurology. 2005; 64(9):1553-62. [PubMed: 15883316]

Hardy JA, Higgins GA. Alzheimer's disease: the amyloid cascade hypothesis. Science. 1992; 256(5054):184-5. [PubMed: 1566067] 
He W, Barrow CJ. The A beta 3-pyroglutamyl and 11-pyroglutamyl peptides found in senile plaque have greater beta-sheet forming and aggregation propensities in vitro than full-length $\mathrm{A}$ beta. Biochemistry. 1999; 38(33):10871-7. [PubMed: 10451383]

Head E, Pop V, Sarsoza F, Kayed R, Beckett TL, Studzinski CM, Tomic JL, Glabe CG, Murphy MP. Amyloid-beta peptide and oligomers in the brain and cerebrospinal fluid of aged canines. $\mathrm{J}$ Alzheimers Dis. 2010; 20(2):637-46. [PubMed: 20164551]

Head E, Pop V, Vasilevko V, Hill M, Saing T, Sarsoza F, Nistor M, Christie LA, Milton S, Glabe C, Barrett E, Cribbs D. A two-year study with fibrillar beta-amyloid (Abeta) immunization in aged canines: effects on cognitive function and brain Abeta. J Neurosci. 2008; 28(14):3555-66. [PubMed: 18385314]

Herring A, Yasin H, Ambree O, Sachser N, Paulus W, Keyvani K. Environmental enrichment counteracts Alzheimer's neurovascular dysfunction in TgCRND8 mice. Brain Pathol. 2008; 18(1): 32-9. [PubMed: 17924982]

Hock C, Konietzko U, Streffer JR, Tracy J, Signorell A, Muller-Tillmanns B, Lemke U, Henke K, Moritz E, Garcia E, Wollmer MA, Umbricht D, de Quervain DJ, Hofmann M, Maddalena A, Papassotiropoulos A, Nitsch RM. Antibodies against beta-amyloid slow cognitive decline in Alzheimer's disease. Neuron. 2003; 38(4):547-54. [PubMed: 12765607]

Holmes C, Boche D, Wilkinson D, Yadegarfar G, Hopkins V, Bayer A, Jones RW, Bullock R, Love S, Neal JW, Zotova E, Nicoll JA. Long-term effects of Abeta42 immunisation in Alzheimer's disease: follow-up of a randomised, placebo-controlled phase I trial. Lancet. 2008; 372(9634):216-23. [PubMed: 18640458]

Holsinger RM, Schnarr J, Henry P, Castelo VT, Fahnestock M. Quantitation of BDNF mRNA in human parietal cortex by competitive reverse transcription-polymerase chain reaction: decreased levels in Alzheimer's disease. Brain Res Mol Brain Res. 2000; 76(2):347-54. [PubMed: 10762711]

Intlekofer KA, Cotman CW. Exercise counteracts declining hippocampal function in aging and Alzheimer's disease. Neurobiol Dis. 2013; 57:47-55. [PubMed: 22750524]

Janus C, Pearson J, McLaurin J, Mathews PM, Jiang Y, Schmidt SD, Chishti MA, Horne P, Heslin D, French J, Mount HT, Nixon RA, Mercken M, Bergeron C, Fraser PE, St George-Hyslop P, Westaway D. A beta peptide immunization reduces behavioural impairment and plaques in a model of Alzheimer's disease. Nature. 2000; 408(6815):979-82. [PubMed: 11140685]

Karran E, Hardy J. Antiamyloid therapy for Alzheimer's disease--are we on the right road? N Engl J Med. 2014; 370(4):377-8. [PubMed: 24450897]

Kitamoto T, Ogomori K, Tateishi J, Prusiner SB. Formic acid pretreatment enhances immunostaining of cerebral and systemic amyloids. Laboratory Investigation. 1987; 57(2):230-6. [PubMed: 2441141]

Lazarov O, Robinson J, Tang YP, Hairston IS, Korade-Mirnics Z, Lee VM, Hersh LB, Sapolsky RM, Mirnics K, Sisodia SS. Environmental enrichment reduces Abeta levels and amyloid deposition in transgenic mice. Cell. 2005; 120(5):701-13. [PubMed: 15766532]

Livak KJ, Schmittgen TD. Analysis of relative gene expression data using real-time quantitative PCR and the 2(-Delta Delta C(T)) Method. Methods. 2001; 25(4):402-8. [PubMed: 11846609]

Lowseth LA, Gillett NA, Gerlach RF, Muggenburg BA. The effects of aging on hematology and serum chemistry values in the beagle dog. Vet Clin Path. 1990; 19(1):13-9. [PubMed: 12684941]

Lu Y, Christian K, Lu B. BDNF: a key regulator for protein synthesis-dependent LTP and long-term memory? Neurobiol Learn Mem. 2008; 89(3):312-23. [PubMed: 17942328]

Masliah E, Hansen L, Adame A, Crews L, Bard F, Lee C, Seubert P, Games D, Kirby L, Schenk D. Abeta vaccination effects on plaque pathology in the absence of encephalitis in Alzheimer disease. Neurology. 2005; 64(1):129-31. [PubMed: 15642916]

Michalski B, Fahnestock M. Pro-brain-derived neurotrophic factor is decreased in parietal cortex in Alzheimer's disease. Brain Res Mol Brain Res. 2003; 111(1-2):148-54. [PubMed: 12654514]

Milgram NW, Adams B, Callahan H, Head E, Mackay W, Thirlwell C, Cotman CW. Landmark discrimination learning in the dog. Learning \& Memory. 1999; 6(1):54-61. [PubMed: 10355524]

Milgram NW, Head E, Muggenburg B, Holowachuk D, Murphey H, Estrada J, Ikeda-Douglas CJ, Zicker SC, Cotman CW. Landmark discrimination learning in the dog: effects of age, an 
antioxidant fortified food, and cognitive strategy. Neurosci Biobehav Rev. 2002; 26(6):679-95. [PubMed: 12479842]

Milgram NW, Head E, Muggenburg BA, Holowachuk D, Murphey H, Estrada J, Ikeda-Douglas CJ, Zicker SC, Cotman CW. Landmark discrimination learning in the dog: effects of age, an antioxidant fortified diet, and cognitive strategy. Neuroscience and Biobehavioral Reviews. 2002; 26(6):679-95. [PubMed: 12479842]

Milgram NW, Head E, Weiner E, Thomas E. Cognitive functions and aging in the dog: Acquisition of nonspatial visual tasks. Behav Neurosci. 1994; 108:57-68. [PubMed: 8192851]

Milgram NW, Head E, Zicker SC, Ikeda-Douglas CJ, Murphey H, Muggenburg B, Siwak C, Tapp D, Cotman CW. Learning ability in aged beagle dogs is preserved by behavioral enrichment and dietary fortification: a two-year longitudinal study. Neurobiol Aging. 2005; 26(1):77-90. [PubMed: 15585348]

Milgram NW, Zicker SC, Head E, Muggenburg BA, Murphey H, Ikeda-Douglas CJ, Cotman CW. Dietary enrichment counteracts age-associated cognitive dysfunction in canines. Neurobiol Aging. 2002; 23(5):737-45. [PubMed: 12392778]

Mirra SS, Heyman A, McKeel D, Sumi SM, Crain BJ, Brownlee LM, Vogel FS, Hughes JP, van Belle G, Berg L. The Consortium to Establish a Registry for Alzheimer's Disease (CERAD). Part II. Standardization of the neuropathologic assessment of Alzheimer's disease. Neurology. 1991; 41(4):479-86. [PubMed: 2011243]

Morgan D, Diamond DM, Gottschall PE, Ugen KE, Dickey C, Hardy J, Duff K, Jantzen P, DiCarlo G, Wilcock D, Connor K, Hatcher J, Hope C, Gordon M, Arendash GW. A beta peptide vaccination prevents memory loss in an animal model of Alzheimer's disease. Nature. 2000; 408(6815):982-5. [PubMed: 11140686]

Murphy MP, Morales J, Beckett TL, Astarita G, Piomelli D, Weidner A, Studzinski CM, Dowling AL, Wang X, Levine H 3rd, Kryscio RJ, Lin Y, Barrett E, Head E. Changes in cognition and amyloidbeta processing with long term cholesterol reduction using atorvastatin in aged dogs. J Alzheimers Dis. 2010; 22(1):135-50.

Neus Bosch M, Pugliese M, Andrade C, Gimeno-Bayon J, Mahy N, Rodriguez MJ. Amyloid-beta immunotherapy reduces amyloid plaques and astroglial reaction in aged domestic dogs. Neurodegener Dis. 2015; 15(1):24-37. [PubMed: 25531153]

Nicoll JA, Wilkinson D, Holmes C, Steart P, Markham H, Weller RO. Neuropathology of human Alzheimer disease after immunization with amyloid-beta peptide: a case report. Nat Med. 2003; 9(4):448-52. [PubMed: 12640446]

Pfeifer M, Boncristiano S, Bondolfi L, Stalder A, Deller T, Staufenbiel M, Mathews PM, Jucker M. Cerebral hemorrhage after passive anti-Abeta immunotherapy. Science. 2002; 298(5597):1379. [PubMed: 12434053]

Poon WW, Blurton-Jones M, Tu CH, Feinberg LM, Chabrier MA, Harris JW, Jeon NL, Cotman CW. beta-Amyloid impairs axonal BDNF retrograde trafficking. Neurobiol Aging. 2011; 32(5):821-33. [PubMed: 19540623]

Pop V, Head E, Hill MA, Gillen D, Berchtold NC, Muggenburg BA, Milgram NW, Murphy MP, Cotman CW. Synergistic effects of long-term antioxidant diet and behavioral enrichment on betaamyloid load and non-amyloidogenic processing in aged canines. J Neurosci. 2010; 30(29):98319. [PubMed: 20660265]

Racke MM, Boone LI, Hepburn DL, Parsadainian M, Bryan MT, Ness DK, Piroozi KS, Jordan WH, Brown DD, Hoffman WP, Holtzman DM, Bales KR, Gitter BD, May PC, Paul SM, DeMattos RB. Exacerbation of cerebral amyloid angiopathy-associated microhemorrhage in amyloid precursor protein transgenic mice by immunotherapy is dependent on antibody recognition of deposited forms of amyloid beta. J Neurosci. 2005; 25(3):629-36. [PubMed: 15659599]

Release PP. Pfizer announces topline results of first of four studies in bapineuzumab phase 3 program. 2012

Russo C, Violani E, Salis S, Venezia V, Dolcini V, Damonte G, Benatti U, D'Arrigo C, Patrone E, Carlo P, Schettini G. Pyroglutamate-modified amyloid beta-peptides--AbetaN3(pE)--strongly affect cultured neuron and astrocyte survival. J Neurochem. 2002; 82(6):1480-9. [PubMed: 12354296] 
Salloway S, Sperling R, Brashear HR. Phase 3 trials of solanezumab and bapineuzumab for Alzheimer's disease. N Engl J Med. 2014; 370(15):1460.

Salloway S, Sperling R, Fox NC, Blennow K, Klunk W, Raskind M, Sabbagh M, Honig LS, Porsteinsson AP, Ferris S, Reichert M, Ketter N, Nejadnik B, Guenzler V, Miloslavsky M, Wang D, Lu Y, Lull J, Tudor IC, Liu E, Grundman M, Yuen E, Black R, Brashear HR. Two phase 3 trials of bapineuzumab in mild-to-moderate Alzheimer's disease. N Engl J Med. 2014; 370(4):322-33. [PubMed: 24450891]

Salloway S, Sperling R, Gilman S, Fox NC, Blennow K, Raskind M, Sabbagh M, Honig LS, Doody R, van Dyck CH, Mulnard R, Barakos J, Gregg KM, Liu E, Lieberburg I, Schenk D, Black R, Grundman M. A phase 2 multiple ascending dose trial of bapineuzumab in mild to moderate Alzheimer disease. Neurology. 2009; 73(24):2061-70. [PubMed: 19923550]

Schenk D, Barbour R, Dunn W, Gordon G, Grajeda H, Guido T, Hu K, Huang J, Johnson-Wood K, Khan K, Kholodenko D, Lee M, Liao Z, Lieberburg I, Motter R, Mutter L, Soriano F, Shopp G, Vasquez N, Vandevert C, Walker S, Wogulis M, Yednock T, Games D, Seubert P. Immunization with amyloid-beta attenuates Alzheimer-disease-like pathology in the PDAPP mouse. Nature. 1999; 400(6740):173-7. [PubMed: 10408445]

Schenk D, Barbour R, Dunn W, Gordon G, Grajeda H, Guido T, Hu K, Huang J, Johnson-Wood K, Khan K, Kholodenko D, Lee M, Liao Z, Lieberburg I, Motter R, Mutter L, Soriano F, Shopp G, Vasquez N, Vandervert C, Walker S, Wogulis M, Yednock T, Games D, Seubert P. Immunization with amyloid- $\beta$ attentuates Alzheimer-disease-like pathology in the PDAPP mouse. Nature. 1999; 400:173-7. [PubMed: 10408445]

Schilling S, Lauber T, Schaupp M, Manhart S, Scheel E, Bohm G, Demuth HU. On the seeding and oligomerization of pGlu-amyloid peptides (in vitro). Biochemistry. 2006; 45(41):12393-9. [PubMed: 17029395]

Schlenzig D, Manhart S, Cinar Y, Kleinschmidt M, Hause G, Willbold D, Funke SA, Schilling S, Demuth HU. Pyroglutamate formation influences solubility and amyloidogenicity of amyloid peptides. Biochemistry. 2009; 48(29):7072-8. [PubMed: 19518051]

Schmidt F, Boltze J, Jager C, Hofmann S, Willems N, Seeger J, Hartig W, Stolzing A. Detection and Quantification of beta-Amyloid, Pyroglutamyl Abeta, and Tau in Aged Canines. J Neuropathol Exp Neurol. 2015; 74(9):912-23. [PubMed: 26247394]

Selkoe DJ, Schenk D. Alzheimer's disease: molecular understanding predicts amyloid-based therapeutics. Annu Rev Pharmacol Toxicol. 2003; 43:545-84. [PubMed: 12415125]

Silverman E. Bapi is a bust: Pfizer \& J\&JAlzheimer Med fails. PharmaBlog. 2012

Siwak-Tapp CT, Head E, Muggenburg BA, Milgram NW, Cotman CW. Region specific neuron loss in the aged canine hippocampus is reduced by enrichment. Neurobiol Aging. 2008; 29(1):39-50. [PubMed: 17092609]

Solomon A, Mangialasche F, Richard E, Andrieu S, Bennett DA, Breteler M, Fratiglioni L, Hooshmand B, Khachaturian AS, Schneider LS, Skoog I, Kivipelto M. Advances in the prevention of Alzheimer's disease and dementia. J Intern Med. 2014; 275(3):229-50. [PubMed: 24605807]

Sperling R, Salloway S, Brooks DJ, Tampieri D, Barakos J, Fox NC, Raskind M, Sabbagh M, Honig LS, Porsteinsson AP, Lieberburg I, Arrighi HM, Morris KA, Lu Y, Liu E, Gregg KM, Brashear HR, Kinney GG, Black R, Grundman M. Amyloid-related imaging abnormalities in patients with Alzheimer's disease treated with bapineuzumab: a retrospective analysis. Lancet Neurol. 2012; 11(3):241-9. [PubMed: 22305802]

Strozyk D, Blennow K, White LR, Launer LJ. CSF Abeta 42 levels correlate with amyloidneuropathology in a population-based autopsy study. Neurology. 2003; 60(4):652-6. [PubMed: 12601108]

Teich AF, Arancio O. Is the amyloid hypothesis of Alzheimer's disease therapeutically relevant? Biochem J. 2012; 446:165-77. [PubMed: 22891628]

Uro-Coste E, Russano de Paiva G, Guilbeau-Frugier C, Sastre N, Ousset PJ, da Silva NA, LavialleGuillotreau V, Vellas B, Delisle MB. Cerebral amyloid angiopathy and microhemorrhages after amyloid beta vaccination: case report and brief review. Clin Neuropathol. 2010; 29(4):209-16. [PubMed: 20569670] 
Viswanathan A, Chabriat H. Cerebral microhemorrhage. Stroke. 2006; 37(2):550-5. [PubMed: 16397165]

Wilcock DM, Colton CA. Immunotherapy, vascular pathology, and microhemorrhages in transgenic mice. CNS Neurol Disord Drug Targets. 2009; 8(1):50_64. [PubMed: 19275636]

Wilcock DM, Gharkholonarehe N, Van Nostrand WE, Davis J, Vitek MP, Colton CA. Amyloid reduction by amyloid-beta vaccination also reduces mouse tau pathology and protects from neuron loss in two mouse models of Alzheimer's disease. J Neurosci. 2009; 29(25):7957-65. [PubMed: 19553436]

Wilcock DM, Hurban J, Helman AM, Sudduth TL, McCarty KL, Beckett TL, Ferrell JC, Murphy MP, Abner EL, Schmitt FA, Head E. Down syndrome individuals with Alzheimer's disease have a distinct neuroinflammatory phenotype compared to sporadic Alzheimer's disease. Neurobiol Aging. 2015; 36(9):2468-74. [PubMed: 26103884]

Wilcock DM, Jantzen PT, Li Q, Morgan D, Gordon MN. Amyloid-beta vaccination, but not nitrononsteroidal anti-inflammatory drug treatment, increases vascular amyloid and microhemorrhage while both reduce parenchymal amyloid. Neuroscience. 2007; 144(3):950-60. [PubMed: 17137722]

Wilcock DM, Rojiani A, Rosenthal A, Levkowitz G, Subbarao S, Alamed J, Wilson D, Wilson N, Freeman MJ, Gordon MN, Morgan D. Passive amyloid immunotherapy clears amyloid and transiently activates microglia in a transgenic mouse model of amyloid deposition. J Neurosci. 2004; 24(27):6144-51. [PubMed: 15240806]

Wilcock DM, Rojiani A, Rosenthal A, Subbarao S, Freeman MJ, Gordon MN, Morgan D. Passive immunotherapy against Abeta in aged APP-transgenic mice reverses cognitive deficits and depletes parenchymal amyloid deposits in spite of increased vascular amyloid and microhemorrhage. J Neuroinflammation. 2004; 1(1):24. [PubMed: 15588287]

Wirths O, Breyhan H, Cynis H, Schilling S, Demuth HU, Bayer TA. Intraneuronal pyroglutamateAbeta 3-42 triggers neurodegeneration and lethal neurological deficits in a transgenic mouse model. Acta Neuropathol. 2009; 118(4):487-96. [PubMed: 19547991]

Wisniewski T, Goni F. Immunotherapeutic approaches for Alzheimer's disease. Neuron. 2015; 85(6): 1162-76. [PubMed: 25789753]

Wolf SA, Kronenberg G, Lehmann K, Blankenship A, Overall R, Staufenbiel M, Kempermann G. Cognitive and physical activity differently modulate disease progression in the amyloid precursor protein (APP)-23 model of Alzheimer's disease. Biol Psychiatry. 2006; 60(12):1314-23. [PubMed: 16806094]

Zajac MS, Pang TY, Wong N, Weinrich B, Leang LS, Craig JM, Saffery R, Hannan AJ. Wheel running and environmental enrichment differentially modify exon-specific BDNF expression in the hippocampus of wild-type and pre-motor symptomatic male and female Huntington's disease mice. Hippocampus. 2010; 20(5):621-36. [PubMed: 19499586] 


\section{Highlights for Review}

- $\quad \mathrm{A} \beta$ immunotherapy in aged canines leads to reduced brain $\mathrm{A} \beta$

- $\quad \mathrm{A} \beta$ immunotherapy increased microhemorrhages and impaired executive function

- Behavioral enrichment improved executive function over time

- $\quad$ A combination of $A \beta$ vaccination with behavioral enrichment leads to cognitive maintenance

- $\quad$ A combination reduced brain $\mathrm{A} \beta$, increased BDNF and increased microhemorrhages. 

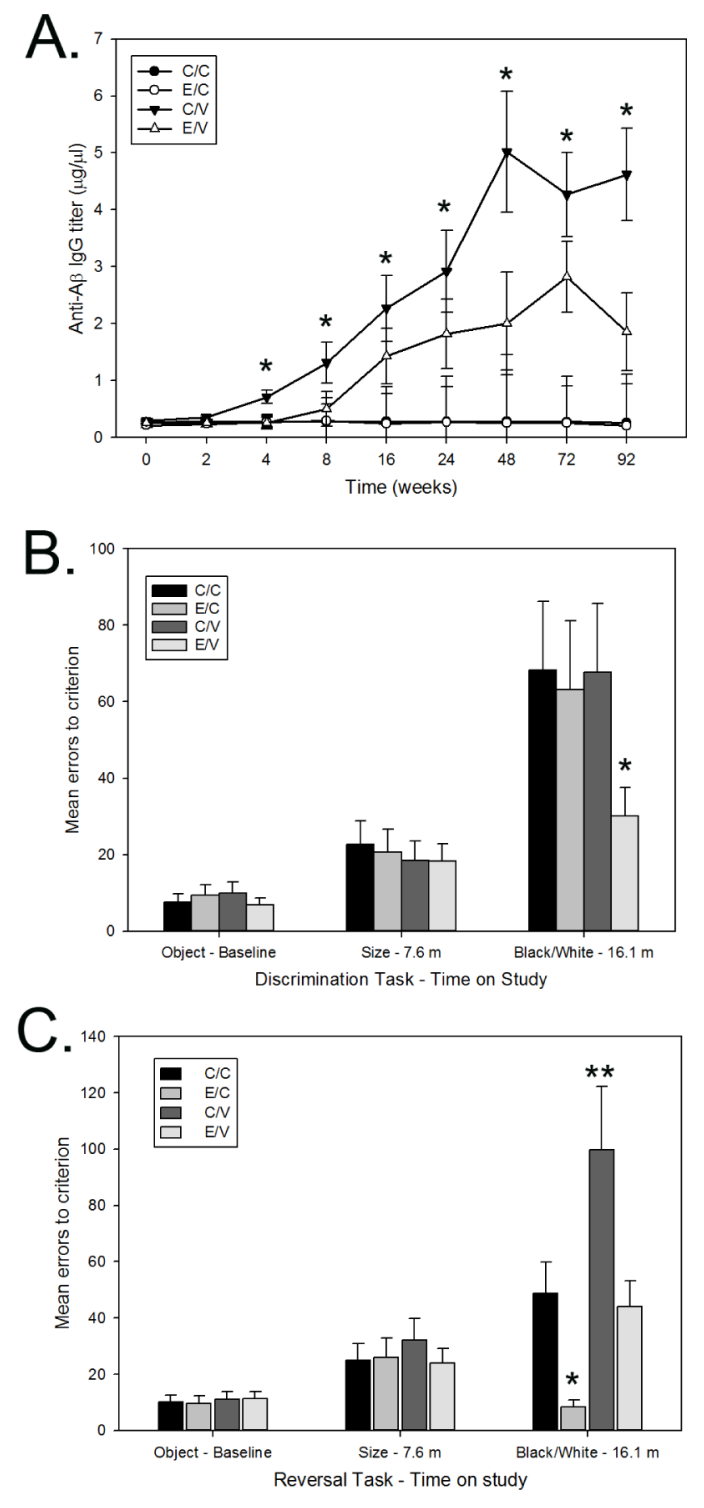

Figure 1.

Effects of the anti-A $\beta 1-42$ vaccine on antibody titers and cognition over time. Anti-fibrillar $\mathrm{A} \beta 1-42 \mathrm{IgG}$ responses increased and were maintained over time in groups receiving the vaccine $(A)(* p<.05$ between VAC $(n=12)$ and non VAC $(n=11))$. To detect treatment effects from all 4 groups over time, a discrimination task (B) was used. Discrimination learning error scores increased over time suggesting both increased task difficult and an underlying aging process $(B)$. The combination treatment group ( $\mathrm{E} / \mathrm{V}(\mathrm{n}=7$ completers) $)$ performed the best overall $(* \mathrm{p}<.05)$ and showed slower decline than either treatment alone. (C) Reversal learning was associated with the $\mathrm{E} / \mathrm{C}$ ( $\mathrm{n}=4$ completers) group having the lowest errors scores over time overall suggesting a maintenance of cognition $(* \mathrm{p}<.05)$. Interestingly, the $\mathrm{C} / \mathrm{V}$ ( $n=3$ completers) group had the highest error scores overall but this was ameliorated by the presence of ENR $(* * \mathrm{p}<.05)$ such that the $\mathrm{E} / \mathrm{V}(\mathrm{n}=7$ completers $)$ group was similar to the $\mathrm{C} / \mathrm{C}$ $(n=7$ completers) group. Error bars represent standard errors of the mean. 
A.

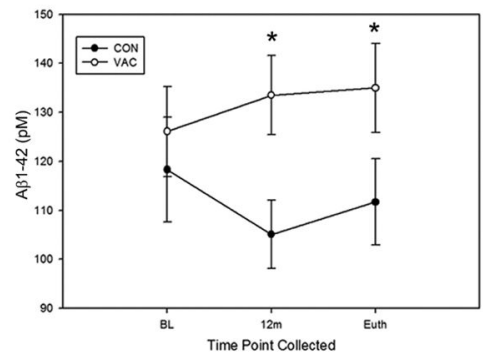

C.

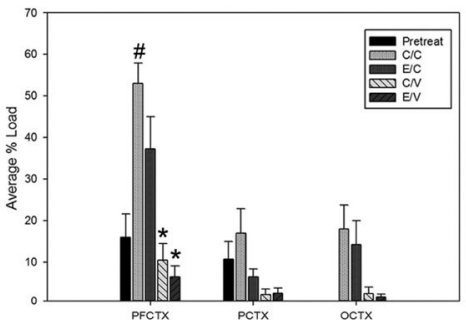

B.

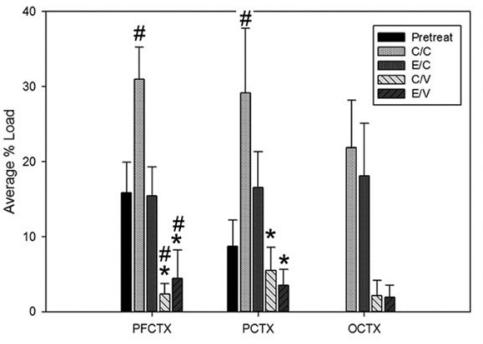

D.

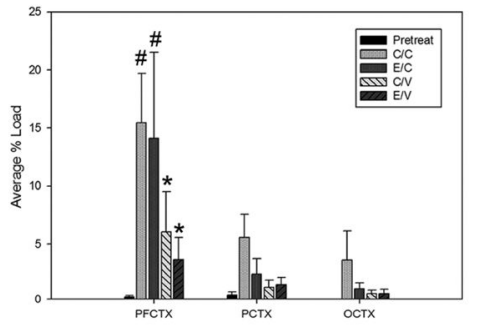



G. -

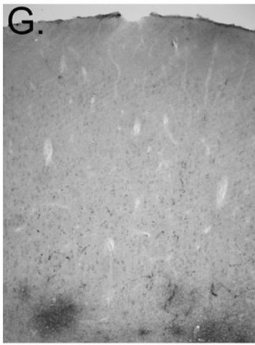

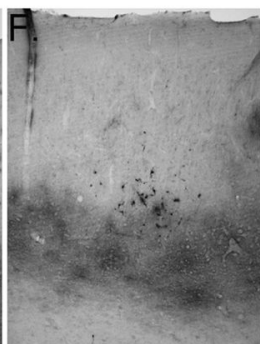

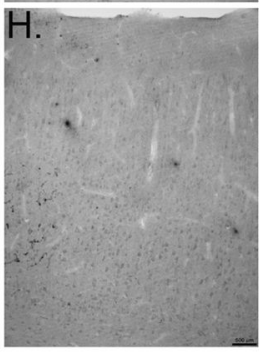

Figure 2.

CSF and brain A $\beta$ changes with treatment. (A) CSF A $\beta 1-42$ was significantly higher in the dogs receiving the VAC at 12 months of treatment $(n=17)$ and at the end of the study $(n=14)$ (*p<.05). (B) A $\beta 42$ plaque loads were variably affected depending on the brain region sampled. In the PFCTX cortex, the $\mathrm{C} / \mathrm{C}(\mathrm{n}=8)$ group had significantly higher $\mathrm{A} \beta 42$ than the pretreatment group $(n=10)$, and the pretreatment group was significantly higher, in turn, than both groups that received the $\operatorname{VAC}(\mathrm{C} / \mathrm{V}(\mathrm{n}=8)$ and $\mathrm{E} / \mathrm{V}(\mathrm{n}=8)(\# \mathrm{p}<.05$ when comparing the pretreatment group to other groups). The pretreatment $A \beta 42$ loads were similar to the ENR only condition (E/C) suggesting a halting of $A \beta 42$ deposition. In both the PFCTX and the PCTX, the $\mathrm{C} / \mathrm{C}$ group had significantly higher $\mathrm{A} \beta 42$ loads than the $\mathrm{C} / \mathrm{V}$ and $\mathrm{E} / \mathrm{V}$ groups $(* \mathrm{p}<.05)$. However in the PFCTX, there was an additional reduction in A $\beta 42$ plaque load in the $\mathrm{E} / \mathrm{C}$ group relative to $\mathrm{C} / \mathrm{C}(* \mathrm{p}<.05$ when comparing $\mathrm{C} / \mathrm{C}$ to other groups) but not in the parietal or occipital cortex. A similar trend was observed in the OCTX but these differences did not reach statistical significance (note - there were no data from the pretreatment group for this brain region). (C) $6 \mathrm{E} 10$ plaque loads were also variably affected depending on the brain region sampled. In the PFCTX cortex, the $\mathrm{C} / \mathrm{C}$ group had significantly higher $6 \mathrm{E} 10$ loads than the pretreatment group $(\# \mathrm{p}<.05$ when comparing the pretreatment group to other groups). The pretreatment $6 \mathrm{E} 10$ loads were similar to all other treatment groups. In the PFCTX, the C/C group had significantly higher 6E10 loads than the $\mathrm{C} / \mathrm{V}$ and $\mathrm{E} / \mathrm{V}$ groups ( $\mathrm{p}$ < $<.05$ when comparing $\mathrm{C} / \mathrm{C}$ to other groups). A similar trend was observed in the PCTX and the OCTX but these differences did not reach statistical significance (note - there were no data from the pretreatment group for the OCTX region). (D) A $\beta \mathrm{pE} 3$ plaque loads were variably affected depending on the brain region sampled. In the prefrontal cortex, the $\mathrm{C} / \mathrm{C}$ and the E/C group had significantly higher $\mathrm{A} \beta \mathrm{pE} 3$ than the pretreatment group $(\# \mathrm{p}<.05$ when comparing the pretreatment group to other groups). In the PFCTX, the C/C group had significantly higher $\mathrm{A} \beta \mathrm{pE} 3$ loads than the $\mathrm{C} / \mathrm{V}$ and $\mathrm{E} / \mathrm{V}$ groups $\left({ }^{*} \mathrm{p}<.05\right.$ when comparing $\mathrm{C} / \mathrm{C}$ to other groups). A similar pattern was observed in the PCTX and the OCTX but these differences did not reach statistical significance (note - there were no data from the 
pretreatment group for OCTX region). Representative A $\beta$ immunostained sections (representing the average \% load for each group) from the PFCTX showing reduced pathology relative to the $\mathrm{C} / \mathrm{C}$ group $(\mathrm{E})$ in the $\mathrm{E} / \mathrm{C}(\mathrm{F}), \mathrm{C} / \mathrm{V}(\mathrm{G})$, and $\mathrm{E} / \mathrm{V}(\mathrm{H})$. 

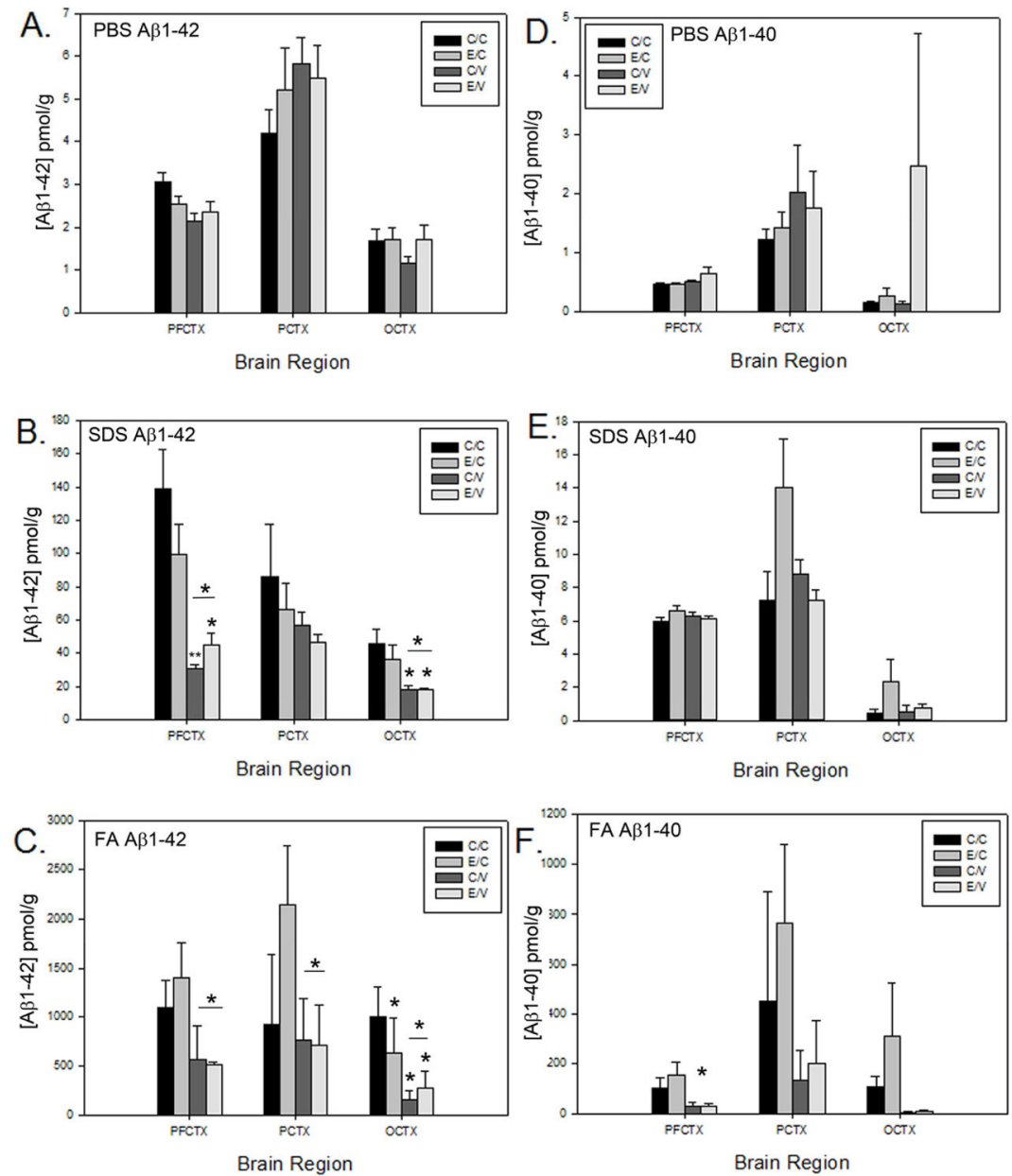

Figure 3.

PBS, SDS and FA extracted $A \beta 1-40$ and $A \beta 1-42$ as a function of treatment and brain region. PBS (A), SDS (B) and FA (C) extracted A $\beta 1-42$ was significantly decreased in dogs receiving the vaccine $(n=18)$ relative to those not vaccinated $(n=16)$ primarily in the PFCTX and OCTX. The PCTX did not show significant changes. In PBS (D), SDS (E) and FA (F) extracted $A \beta 1-40$ measures, fewer differences were noted except the vaccine led to significant decreases in PFCTX and OCTX A $\beta 1-40$ in the FA fraction. Bars indicate group averages, error bars are standard errors of the mean. Lines with * indicate significant group differences in the VAC group from the non vaccine group at the $\mathrm{p}<.05$ level. 

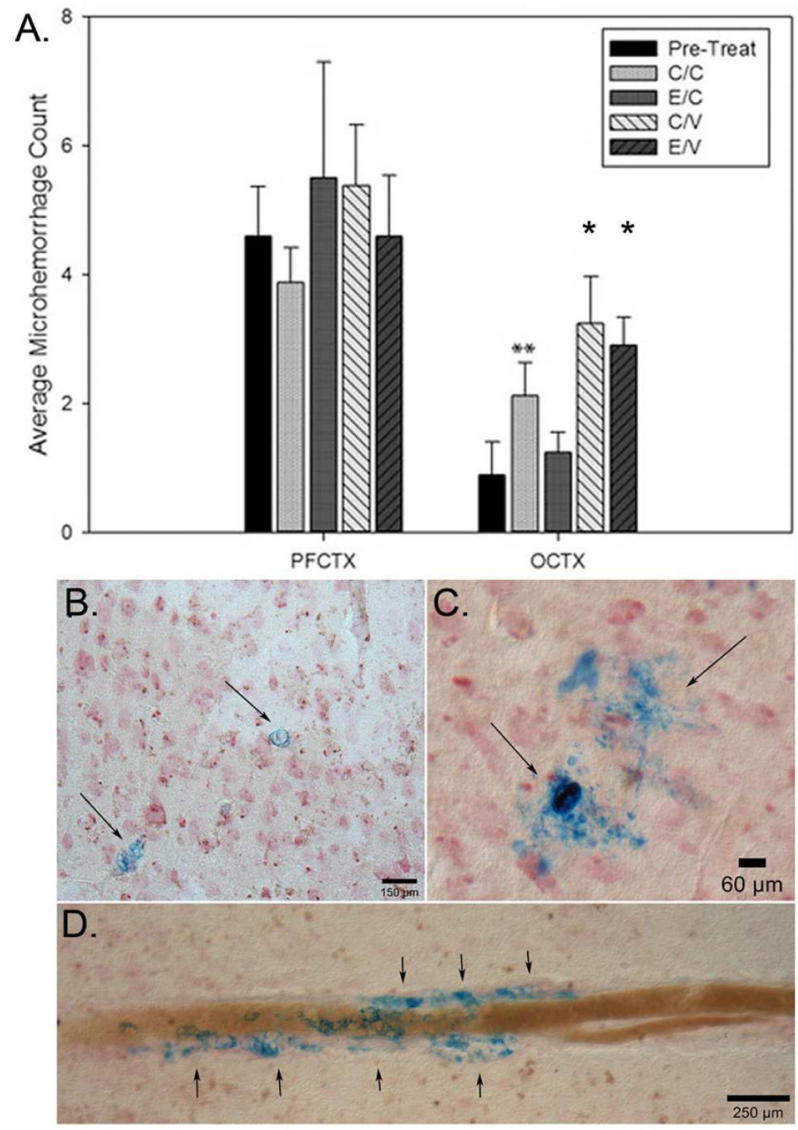

Figure 4.

An $A \beta$ vaccine increases the frequency of microhemorrhages. The average frequency of microhemorrhages was unchanged in the PFCTX. However, in the OCTX there were increased mean numbers of microhemorrhages in both groups of vaccinated dogs $(n=18)$ $(* \mathrm{p}<.05)$ as compared with the $\mathrm{C} / \mathrm{C} \operatorname{dogs}(\mathrm{A})$. Untreated aged dogs $(\mathrm{n}=8)$ had more microhemorrhages than dogs 2 years younger $(n=10)(* * p<.05)$. Dogs provided with behavioral enrichment only $(\mathrm{E} / \mathrm{C}(\mathrm{n}=18)$ had an equivalent number of microhemorrhages compared with dogs 2 years younger. Error bars represent standard errors of the mean. Examples of Prussian blue staining in the B. PFCTX of a dog in the E/V group at lower magnification showing microhemorrhages (arrows) and C. higher magnification (arrows). D shows a blood vessel with a microhemorrhage in the OCTX of a dog receiving the vaccine alone (arrows). 


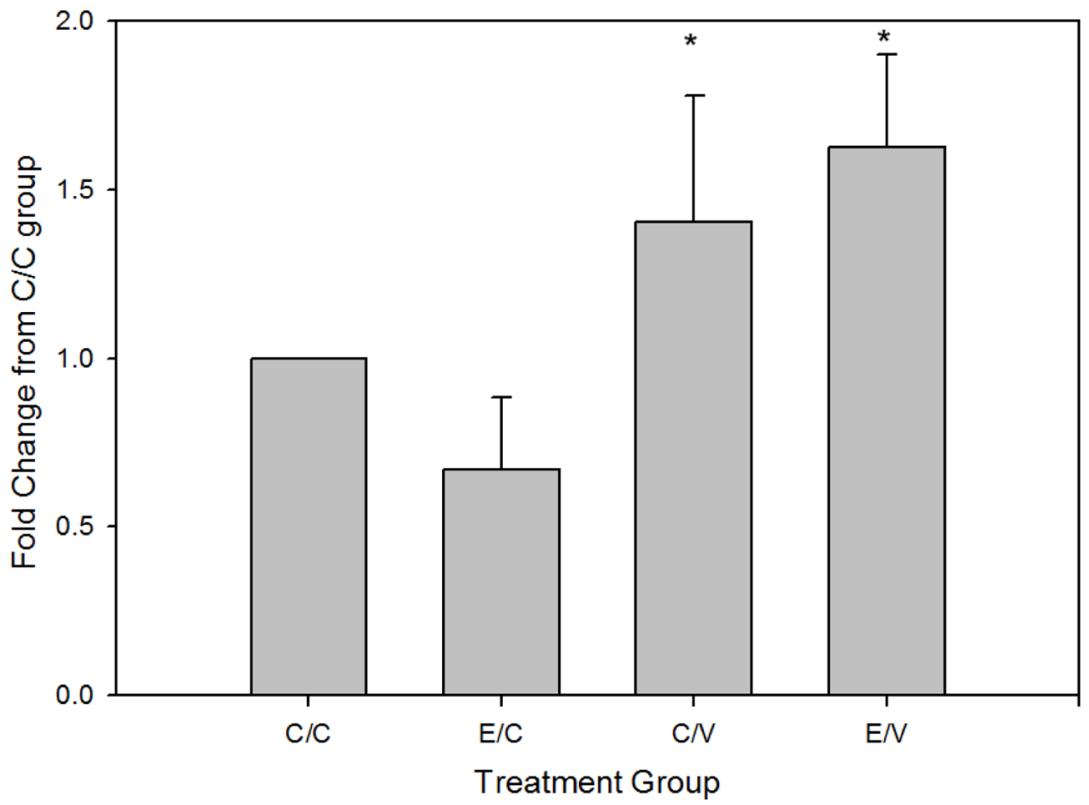

Figure 5.

Parietal BDNF mRNA levels as a function of treatment. Dogs provided with either the A $\beta$ vaccine alone $(n=8)$ or in combination with behavioral enrichment $(n=10)$ show significantly increased levels of parietal BDNF mRNA than untreated animals $(* \mathrm{p}<.05)$. Dogs provided with only behavioral enrichment $(n=8)$ are not significantly different from controls $(n=8)$. 

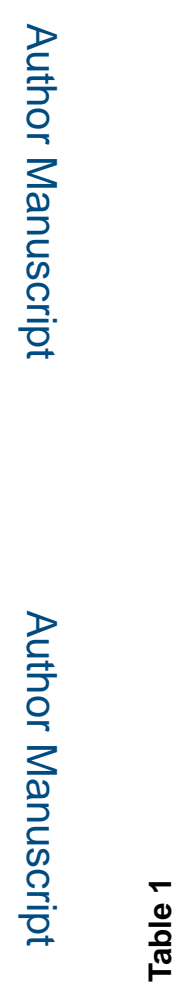

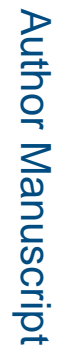

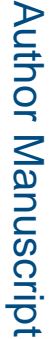

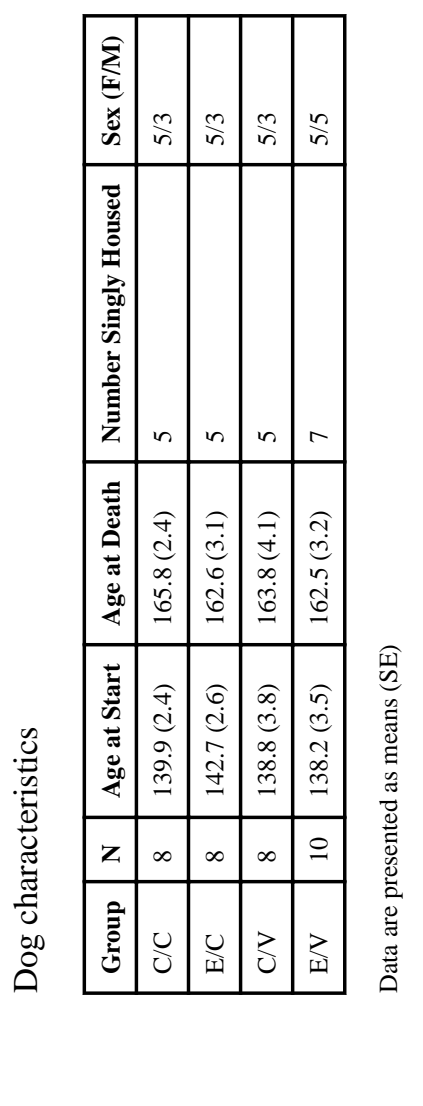

Neurobiol Aging. Author manuscript; available in PMC 2018 January 01. 
Table 2

Study timeline

\begin{tabular}{|l|l|l|}
\hline Cognitive Task & Time on Treatment (months) & Number of Injections \\
\hline Baseline Discrimination Learning & 0 & 0 \\
\hline Baseline Discrimination Reversal & 0 & 0 \\
\hline Spatial Maximal Memory & 0 & 0 \\
\hline Spatial Memory & 0 & 0 \\
\hline Landmark Discrimination * & 1 & 2 \\
\hline Oddity Discrimination * & 4.3 & 5 \\
\hline Size Discrimination and Reversal & 7.6 & 10 \\
\hline T1 Spatial Maximal Memory & 9.4 & 11 \\
\hline T1 Spatial Memory & 11.9 & 14 \\
\hline T2 Landmark Discrimination & 15.2 & 18 \\
\hline Black/White Discrimination and Reversal & 16.1 & 19 \\
\hline T2 Spatial Memory & 18.1 & 21 \\
\hline Brain Tissue Harvested & 19.6 & 23 \\
\hline
\end{tabular}

tasks given to the behavioral enrichment group animals only. 
Table 3

Summary of outcome measures*

\begin{tabular}{|c|c|c|c|c|}
\hline & Outcome Measure & $\mathrm{E} / \mathrm{C}$ & $\mathrm{C} / \mathrm{V}$ & $\mathbf{E} / \mathbf{V}$ \\
\hline & $\mathrm{A} \beta$ antibody titers & $\mathrm{N} / \mathrm{C}$ & Increased & Increased \\
\hline \multirow{5}{*}{ Cognition } & Landmark Discrimination & $\mathrm{N} / \mathrm{C}$ & N/A & $\mathrm{N} / \mathrm{C}$ \\
\hline & Oddity Discrimination & $\mathrm{N} / \mathrm{C}$ & N/A & $\mathrm{N} / \mathrm{C}$ \\
\hline & Repeated Visual Discrimination & $\mathrm{N} / \mathrm{C}$ & $\mathrm{N} / \mathrm{C}$ & Improved \\
\hline & Repeated Reversal Learning & Improved & Impaired & $\mathrm{N} / \mathrm{C}$ \\
\hline & Spatial Memory & $\mathrm{N} / \mathrm{C}$ & $\mathrm{N} / \mathrm{C}$ & $\mathrm{N} / \mathrm{C}$ \\
\hline \multirow{2}{*}{ CSF } & $\mathrm{CSF} A \beta 1-40$ & $\mathrm{~N} / \mathrm{C}$ & $\mathrm{N} / \mathrm{C}$ & $\mathrm{N} / \mathrm{C}$ \\
\hline & $\mathrm{CSF} A \beta 1-42$ & Decreased & Increased & Increased \\
\hline \multirow{12}{*}{ A $\beta$ Plaques } & $\mathrm{A} \beta 1-42$ Plaques & & & \\
\hline & Prefrontal & Decreased & Decreased & Decreased \\
\hline & Parietal & $\mathrm{N} / \mathrm{C}$ & Decreased & Decreased \\
\hline & Occipital & $\mathrm{N} / \mathrm{C}$ & Decreased & Decreased \\
\hline & $\mathrm{A} \beta$ total $(6 \mathrm{E} 10)$ & & & \\
\hline & Prefrontal & $\mathrm{N} / \mathrm{C}$ & Decreased & Decreased \\
\hline & Parietal & $\mathrm{N} / \mathrm{C}$ & Decreased & Decreased \\
\hline & Occipital & $\mathrm{N} / \mathrm{C}$ & Decreased & Decreased \\
\hline & A $\beta$ pE3 Plaques & & & \\
\hline & Prefrontal & $\mathrm{N} / \mathrm{C}$ & Decreased & Decreased \\
\hline & Parietal & $\mathrm{N} / \mathrm{C}$ & $\mathrm{N} / \mathrm{C}$ & $\mathrm{N} / \mathrm{C}$ \\
\hline & Occipital & $\mathrm{N} / \mathrm{C}$ & $\mathrm{N} / \mathrm{C}$ & $\mathrm{N} / \mathrm{C}$ \\
\hline \multirow{15}{*}{$\mathrm{A} \beta$ ELISA } & PBS soluble $A \beta 1-42$ & $\mathrm{~N} / \mathrm{C}$ & $\mathrm{N} / \mathrm{C}$ & $\mathrm{N} / \mathrm{C}$ \\
\hline & PBS soluble A $\beta$ 1-40 & $\mathrm{N} / \mathrm{C}$ & $\mathrm{N} / \mathrm{C}$ & $\mathrm{N} / \mathrm{C}$ \\
\hline & SDS soluble $A \beta 1-42$ & & & \\
\hline & Prefrontal & $\mathrm{N} / \mathrm{C}$ & Decreased & Decreased \\
\hline & Parietal & $\mathrm{N} / \mathrm{C}$ & $\mathrm{N} / \mathrm{C}$ & $\mathrm{N} / \mathrm{C}$ \\
\hline & Occipital & $\mathrm{N} / \mathrm{C}$ & $\mathrm{N} / \mathrm{C}$ & $\mathrm{N} / \mathrm{C}$ \\
\hline & SDS soluble $A \beta 1-40$ & $\mathrm{~N} / \mathrm{C}$ & $\mathrm{N} / \mathrm{C}$ & $\mathrm{N} / \mathrm{C}$ \\
\hline & FA soluble $A \beta 1-42$ & & & \\
\hline & Prefrontal & $\mathrm{N} / \mathrm{C}$ & Decreased & Decreased \\
\hline & Parietal & $\mathrm{N} / \mathrm{C}$ & Decreased & Decreased \\
\hline & Occipital & Decreased & Decreased & Decreased \\
\hline & FA soluble $A \beta 1-40$ & & & \\
\hline & Prefrontal & $\mathrm{N} / \mathrm{C}$ & Decreased & Decreased \\
\hline & Parietal & $\mathrm{N} / \mathrm{C}$ & $\mathrm{N} / \mathrm{C}$ & $\mathrm{N} / \mathrm{C}$ \\
\hline & Occipital & $\mathrm{N} / \mathrm{C}$ & $\mathrm{N} / \mathrm{C}$ & $\mathrm{N} / \mathrm{C}$ \\
\hline & Microhemorrhages & & & \\
\hline
\end{tabular}




\begin{tabular}{|l|l|l|l|l|}
\hline & Outcome Measure & E/C & C/V & E/V \\
\hline \multirow{3}{*}{} & Prefrontal & N/C & N/C & N/C \\
\cline { 2 - 5 } & Occipital & N/C & Increased & Increased \\
\hline Growth Factor (BDNF) & N/C & Increased & Increased \\
\hline
\end{tabular}

Increases/decreases were statistically significantly different from the C/C group. N/C - no change from C/C group N/A - not applicable 